DOI: 10.1002/adma. 201702992

\title{
Nanodroplet-Containing Polymers for Efficient Low-Power Light Upconversion
}

Roberto Vadrucci, Angelo Monguzzi, Felipe Saenz, Bodo D. Wilts, Yoan C. Simon*, and Christoph Weder*

Dr. Roberto Vadrucci ${ }^{[+]}$, Felipe Saenz, Dr. Bodo D. Wilts, Prof. Yoan C. Simon ${ }^{[\|]}$, Prof. Christoph Weder, Adolphe Merkle Institute, University of Fribourg

Chemin des Verdiers 4, CH-1700, Fribourg, Switzerland

E-mail: christoph.weder@unifr.ch, Yoan.Simon@usm.edu

Prof. Angelo Monguzzi

Dipartimento di Scienza dei Materiali, Università of Milano-Bicocca, via Cozzi 55, I-20125 Milano, Italy

[+] Present address: Melville Laboratory for Polymer Synthesis, Department of Chemistry, University of Cambridge, Lensfield Road, Cambridge CB2 1EW, UK.

[||] Present address: School of Polymers and High Performance Materials, University of Southern Mississippi, 118 College Dr. \#5050, Hattiesburg, MS 39406, USA.

Keywords: Triplet-Triplet Annihilation Upconversion, Optically Active Materials, SelfAssembly, Polymeric Materials, Luminescence 


\section{Abstract}

Triplet-triplet-annihilation-based photon upconversion (TTA-UC) permits the conversion of light into radiation of higher energy and involves a sequence of photophysical processes between two dyes. ${ }^{[1-3]}$ In contrast to other upconversion schemes, TTA-UC allows the frequency-shifting of low-intensity light, which makes it particularly suitable for solar energy harvesting technologies. ${ }^{[4,5]}$ High upconversion yields can be observed for low viscosity solutions of dyes, but in solid materials, ${ }^{[6-9]}$ which are better suited for integration in devices ${ }^{[10]}$ the process is usually less efficient. Here we show that this problem can be solved by using transparent nanodroplet-containing polymers that consist of a continuous polymer matrix and a dispersed liquid phase containing the upconverting dyes. These materials can be accessed by a simple one-step procedure that involves the free-radical polymerization of a microemulsion of hydrophilic monomers, a lipophilic solvent, the upconverting dyes and a surfactant. Using this approach, several materials with glassy and rubbery matrices were explored and a range of dye pairs that enable TTA-UC in different spectral regions were utilized. Under ambient conditions, the materials displayed upconversion efficiencies of up to $\sim 15 \%$, approaching the performance of optimized oxygen-free reference solutions. Since oxygen is known to interfere with the TTA-UC process, the data suggest that the matrix not only serves as mechanically coherent carrier for the upconverting liquid phase, but also provides good protection from atmospheric oxygen. ${ }^{[7,11-14]}$ Given their simplicity and versatility, the fabrication process and materials concept presented here could be the basis for further developments of upconverting systems for solar harvesting applications, water sterilization and imaging, and permit access to other types of advanced optical materials. ${ }^{[4,5,10,15]}$ 


\section{Main Text}

The conversion of light into photons of higher energy based on sensitized triplet-triplet annihilation upconversion (TTA-UC) is a promising photon-managing strategy that permits upconverting non-coherent light of low intensity. ${ }^{[5]}$ The photophysical steps involved in the process include the absorption of incident photons by a sensitizer, the generation of sensitizer triplets through intersystem crossing, and a triplet-triplet energy transfer (TTET) step through which the triplets of an emitter are populated (Figure 1). The subsequent annihilation of two emitter triplets (TTA) can generate an emitter singlet, which relaxes to the ground state under fluorescence. ${ }^{[1,2,4]}$ The TTET and TTA steps require the molecular orbitals of the involved species to overlap, ${ }^{[3]}$ which makes TTA-UC efficient in low viscosity solutions, where the dye molecules enjoy significant translational mobility and the collisional probability is high. ${ }^{[2-4,13 \text {, }}$ 16] However, the use of liquids (solutions or emulsions) complicates the fabrication of technologically useful devices. To enable TTA-UC in solid materials, UC dyes were included in rubbery polymers ${ }^{[6,17,18]}$ and polymer-based ${ }^{[8]}$ or supramolecular gels. ${ }^{[19-22]}$ Efficient TTAUC has indeed been demonstrated in gels, but as their composition is dominated by a solvent, these materials suffer from the same limitations as solutions. Alternatively, the emitter can be incorporated in high concentration, for example in organic ${ }^{[23]}$ or polymeric ${ }^{[24,25]}$ glasses. In this case, no molecular motion is needed, as excitons can migrate between nearby chromophores before they eventually annihilate. ${ }^{[23-27]}$ This sequence is particularly efficient in ordered chromophore arrays. ${ }^{[14,28]}$ Nevertheless, the highest TTA-UC efficiency reported for rigid materials $(<5 \%)^{[24,26,29]}$ is much lower than that of solutions containing the same chromophores. Upconversion efficiencies of $>15 \%$ have been reported for several dye systems in deaerated organic solvents (e.g. DPA/PdOEP: $18 \%$ in toluene, ${ }^{[30]}$ DPA/PtOEP: $>23 \%$ in ethanol or tetrahydrofuran, ${ }^{[3,28,31]}$ perylene/PdTPBP: $38 \%$ in tetrahydrofuran) ${ }^{[32]}$ whereas microemulsions (e.g. DNAMe/PdMeTPP: $16 \%$, oil-in-water) $\left.{ }^{[16,} 33\right]$ or more sophisticated mixtures ${ }^{[13,34]}$ have been proposed for efficient upconversion under ambient conditions. Suspensions of nanoparticulate ${ }^{[35-38]}$ or encapsulated systems ${ }^{[39-42]}$ and some organic solutions $^{[8,16]}$ display good but usually lower TTA-UC efficiencies when operated under ambient conditions. 


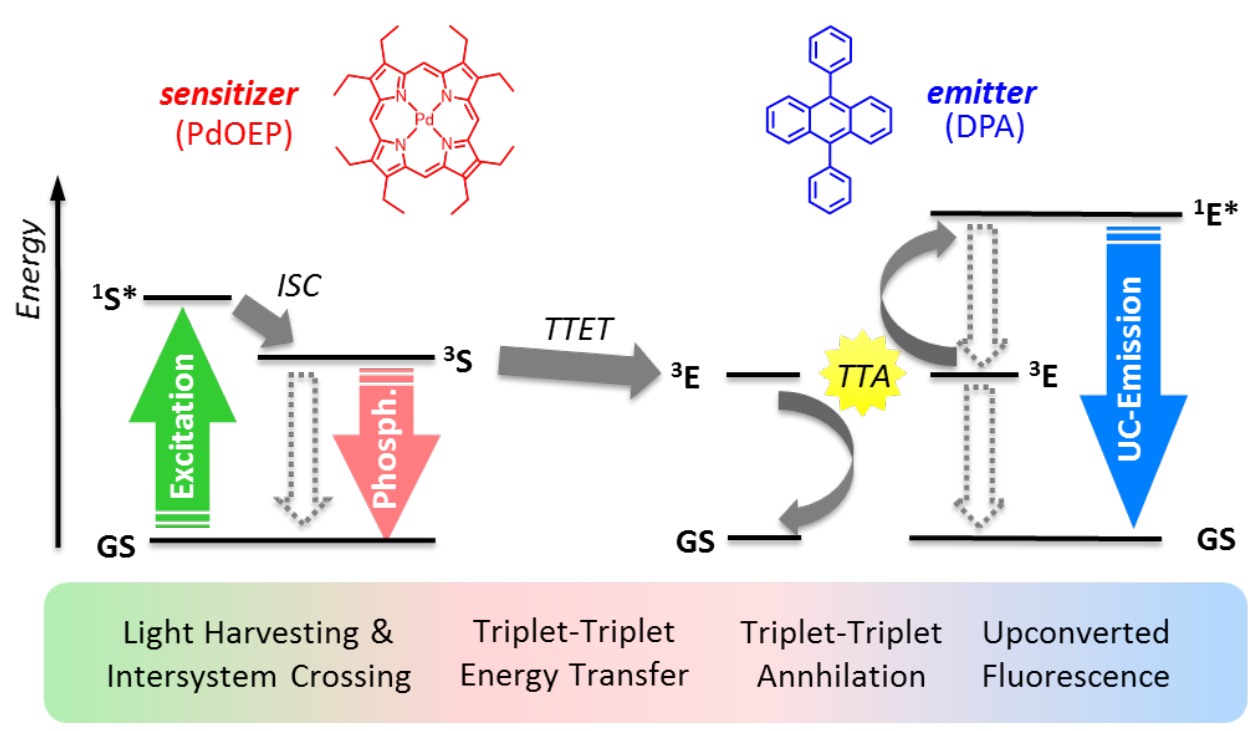

Figure 1: Photophysical processes in triplet-triplet annihilation upconversion (TTA-UC). Energy level diagram and schematic explanation of the TTA-UC mechanism that exploits Pd(II) octaethylporphyrin (PdOEP) as light-harvester/sensitizer and 9,10-diphenylanthracene (DPA) as annihilator/emitter for green-to-blue photon upconversion. ISC: intersystem crossing; TTET: triplettriplet energy transfer; GS: ground state; ${ }^{1} \mathrm{~S}^{*},{ }^{3} \mathrm{~S},{ }^{1} \mathrm{E}^{*},{ }^{3} \mathrm{E}$ : first singlet excited $\left({ }^{1, *}\right)$ or triplet state $\left({ }^{3}\right)$ of the sensitizer and emitter.

Solid polymers containing the TTA-UC sensitizer/emitter pair in a dispersed liquid phase could merge the efficient upconversion properties of solutions with the features offered by solid matrices. ${ }^{[7,10,12,43]}$ Initial embodiments of this general idea involved multistep encapsulation procedures or afforded opaque materials with limited mechanical properties. ${ }^{[7}$, 12] These obstacles can be overcome by fabricating nanodroplet-containing polymers that consist of a polymer matrix and a dispersed liquid phase, in which the upconverting dyes are dissolved (Figure 2a). Such materials can be accessed by a simple one-step process that was inspired by protocols used to create polymerizable lyotropic liquid-crystalline (LC) assemblies $^{[44]}$ and polymerization-induced phase separation techniques. ${ }^{[45,46]}$ The former require LC building blocks and typically afford gels, ${ }^{[47]}$ while the latter use macromonomers to achieve nanophase separation. By contrast, the nanodroplet-containing polymers introduced here can be made by polymerization of microemulsions of hydrophilic monomers, a lipophilic solvent, and a surfactant. 
A first series of nanodroplet-containing polymers with a cross-linked glassy polymer matrix was prepared under ambient conditions by the redox-initiated free-radical polymerization of a mixture of the hydrophilic monomers 2-hydroxyethyl methacrylate (HEMA), methacrylic acid (MAA) and triethylene glycol dimethacrylate (TEG-diMA, cross-linker), a small amount (10 wt $\%)$ of the lipophilic, low-volatility liquid 1-tert-butyl-3,5-dimethyl benzene (BMB), and the surfactant cetyltrimethylammonium bromide (CTAB, Figure 2c). The mixture also contained ethylene glycol as refractive-index modifier and plasticizer for the polymer matrix, and the well-known TTA-UC sensitizer/emitter pair palladium(II) octaethylporphyrin (PdOEP, $\left.2 \times 10^{-5} \mathrm{M}\right)$ and 9,10-diphenylanthracene (DPA, $\left.1.5 \times 10^{-2} \mathrm{M}\right)($ Figure 1$) .{ }^{[2,3,17]}$ The sensitizer/emitter concentrations were selected on the basis of solution experiments and the goal of achieving a significant absorptance at $543 \mathrm{~nm} \cdot{ }^{[3]}$ The reaction afforded a rigid, tough, material that was almost colorless if the dyes were omitted (Figure 2b, Supporting Figure S1, Supporting Movie M1). The dye-free nanodroplet-containing glassy polymer shows a transmittance of $>75 \%$ over a path of $1 \mathrm{~cm}$ in the entire visible regime, which confirms that the matching of the refractive indices of the amorphous matrix and the dispersed liquid phase allows suppressing interfacial scattering effects (Supporting Figure S2). Scanning electron microscopy (SEM) images of the dye-free (Figure 2d) and dye-containing materials (Supporting Figure S3a) reveal similar nanophase-separated structures. The images show clearly that the continuous polymer phase contains the solvent (BMB) in the forms of nanodroplets that have feature dimensions of $\sim 20-100 \mathrm{~nm}$ and occasionally appear to merge into elongated channels. The absence of phase segregation observed in a reference material prepared without the surfactant (Supporting Figure S3b) and the differences in the small-angle X-ray scattering data (Supporting Figure S4) indicate that the surfactant is essential for the formation of the liquid nanodroplets even though no detailed structural information could be extracted from the latter measurement. The differential scanning calorimetry trace displays only one glass transition at $\sim 48-52{ }^{\circ} \mathrm{C}$ (Supporting Figure S5), which is consistent with the 
formation of an amorphous, ethylene-glycol-plasticized poly(HEMA-co-MAA-co-TEGdiMA) copolymer.

a

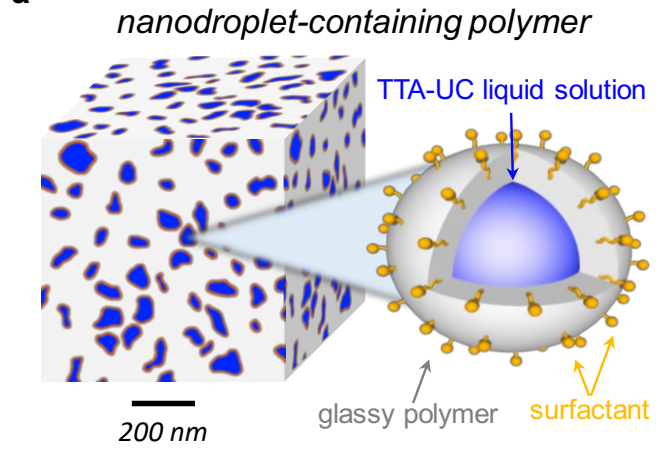

b

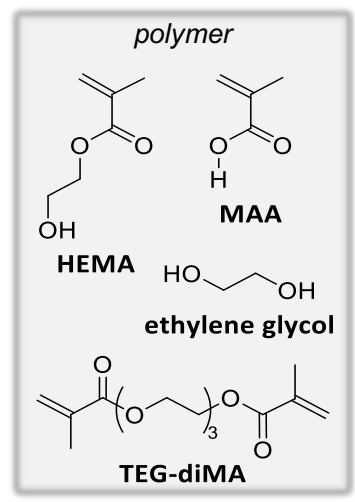

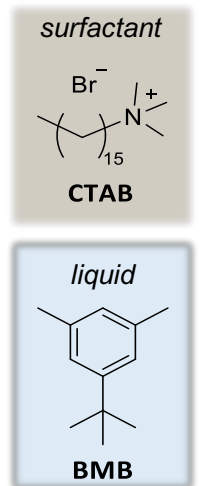

C

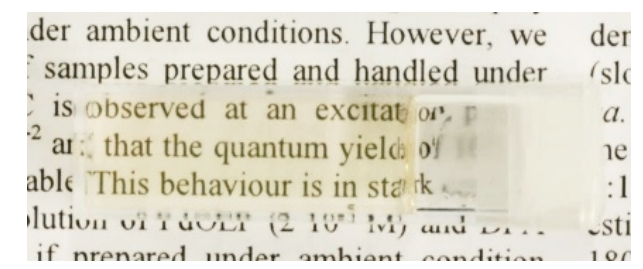

d

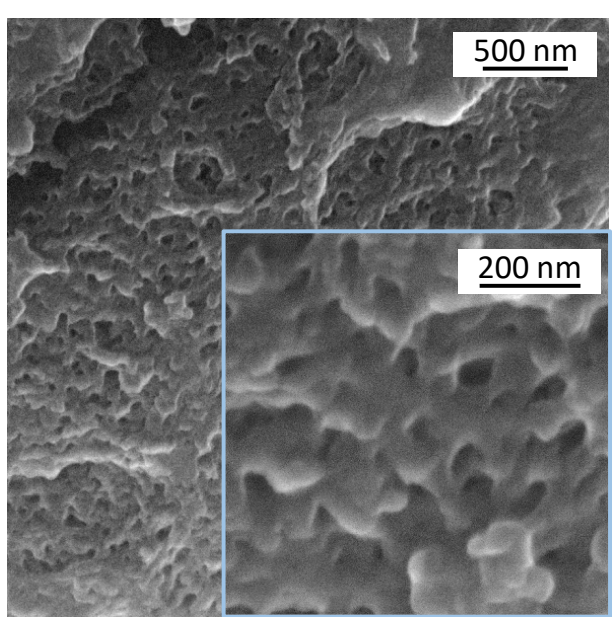

Figure 2: Nanodroplet-containing polymers. (a) Rendering of the materials' morphology. (b) Chemical structures of the constituents forming the glassy polymer, the surfactant, and the liquid phase. (c) Photograph and (d) scanning electron microscopy images of a dye-free nanodroplet-containing glassy polymer. The SEM images reveal a continuous polymer phase featuring partially interconnected pores with typical diameter of $\sim 20-100 \mathrm{~nm}$; the inset is a magnification of a portion of the SEM image.

On account of their nonpolar nature, the upconverting dyes were expected to preferably reside in the hydrophobic liquid nanodroplets (accounting for 10-15 wt \% of the material) and exhibit solution-like TTA-UC. To test this hypothesis, the optical properties of dye-doped nanodroplet-containing polymer glasses were studied by means of continuous wave and timeresolved optical spectroscopy, employing BMB solutions of the dyes as reference system. The absorption and steady-state photoluminescence (PL) spectra of samples containing either PdOEP or DPA, or the DPA/PdOEP mixture match the spectra of corresponding solutions well (Figure 3a and Supporting Figure S6), ${ }^{[17]}$ demonstrating that the inclusion process did not affect the electronic properties of the chromophores. The dynamics of the characteristic blue 
DPA fluorescence at $431 \mathrm{~nm}$ and red PdOEP phosphorescence at $666 \mathrm{~nm}$ were studied using time-resolved PL spectroscopy and provided insights about the location of the dyes. The timeresolved intensity decay of the blue DPA emission shows a bi-exponential behavior in nanodroplet-containing polymers comprising either both dyes or DPA only (Figure 3b). This suggests the coexistence of two sub-populations of emitters having characteristic PL lifetimes of $\sim 6$ and $\sim 14 \mathrm{~ns}$, respectively. The faster lifetime is similar to the one observed for a DPA solution in BMB (7.2 ns, Figure 3b), whereas the longer decay appears to be associated with aggregated DPA molecules embedded in the rigid matrix. The relative contributions of the two decay components obtained from bi-exponential fits of the data indicate that $\sim 35 \%$ of the emitter molecules reside in the liquid phase. Their majority appears to be included in the solid matrix, where they neither contribute to nor hamper the TTA-UC process because the sensitizer molecules appear to reside predominantly in the liquid phase (vide infra).

Upon irradiation with green laser light at $543 \mathrm{~nm}\left(275 \mathrm{~mW} \mathrm{~cm}^{-2}\right)$ the DPA/PdOEP doped nanodroplet-containing polymer displayed, even under ambient conditions, bright blue emission (Figure 3c, left), while the reference materials containing either PdOEP or DPA only displayed red phosphorescence or scattered green light, respectively (Figure 3c, right). While dominated by the upconverted blue emission, the PL spectrum of the DPA/PdOEP-containing material shows a weak emission band at $666 \mathrm{~nm}$ (Figure 3d), which is associated with residual PdOEP phosphorescence and suggests that the sensitizer-emitter TTET is not quantitative. Time-resolved phosphorescence experiments revealed a single exponential decay with a lifetime $\tau_{p h}=1.50 \mathrm{~ms}$, which is much higher than the value of $20 \mu$ s observed in the degassed BMB solution, but comparable to the radiative decay of PdOEP. ${ }^{[48]}$ Thus, these findings suggest that the weak red luminescence belongs to a small portion of the sensitizer that is embedded in the polymer phase, where it is well protected from oxygen and solvent quenching (Supporting Figure S7). ${ }^{[3]}$ No fast emission component could be detected, which 
indicates that for the sensitizer molecules incorporated in the liquid phase the TTET yield is $100 \%$ and that emitter-to-sensitizers back energy transfer is negligible. ${ }^{[3]}$ The same excitation conditions were used to acquire the upconversion emission spectra of degassed and nondegassed DPA/PdOEP reference solutions in BMB (Figure 3d). The non-degassed solution showed neither up- nor down-converted emission, whereas the degassed solution emits bright upconverted blue light, indicating triplet quenching by molecular oxygen in the former. ${ }^{[1]}$ The PL spectrum of the DPA/PdOEP nanodroplet-containing polymer mirrors the features observed for the degassed solution, and the upconverted emission intensities of the two samples are comparable, although the polymer had been prepared under ambient conditions. This material retained $\sim 50 \%$ of its initial upconversion efficiency after storage for six weeks or after 13.5 hours of continuous operation under $10 \mathrm{~mW} \mathrm{~cm} \mathrm{~cm}^{-2}$ irradiation at $543 \mathrm{~nm}$ (Supporting Figures S8-S10). A comparison of plots of the upconverted emission intensity vs. time (Supporting Figures S9-10) recorded for polymers prepared under ambient conditions and inert atmosphere, respectively, suggests that the former contain traces of oxygen, which are, however, rapidly consumed upon irradiation. Taken together, these results highlight that the glassy polymer matrix protects the liquid nanophase surprisingly well from atmospheric oxygen and that the use of a volatile liquid component is no fundamental obstacle for longevity, although the stability needs to be clearly improved before technological exploitation in devices is feasible. Strategies to achieve this include the use of dyes with better (photo)stability (DPA is well-known undergo (photo)oxidation to an endoperoxide and dimerize, respectively, $\left.{ }^{[2,49,50]}\right)$, the addition of stabilizers, ${ }^{[34,51,52]}$ a less volatile solvent, ${ }^{[53,54]}$ and perhaps additional barrier layers. ${ }^{[7]}$ 

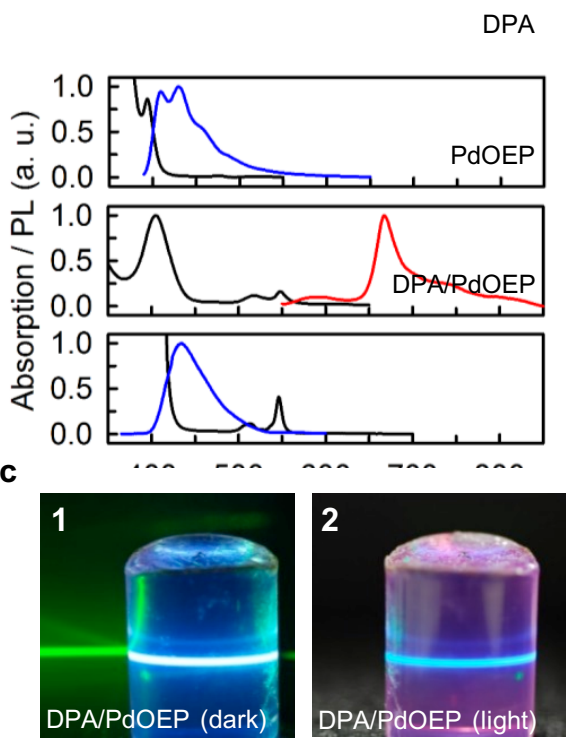

d

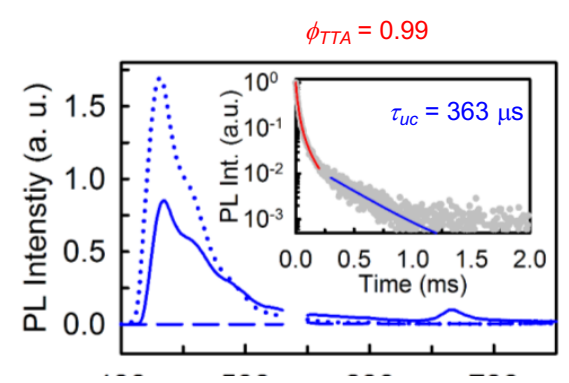

b
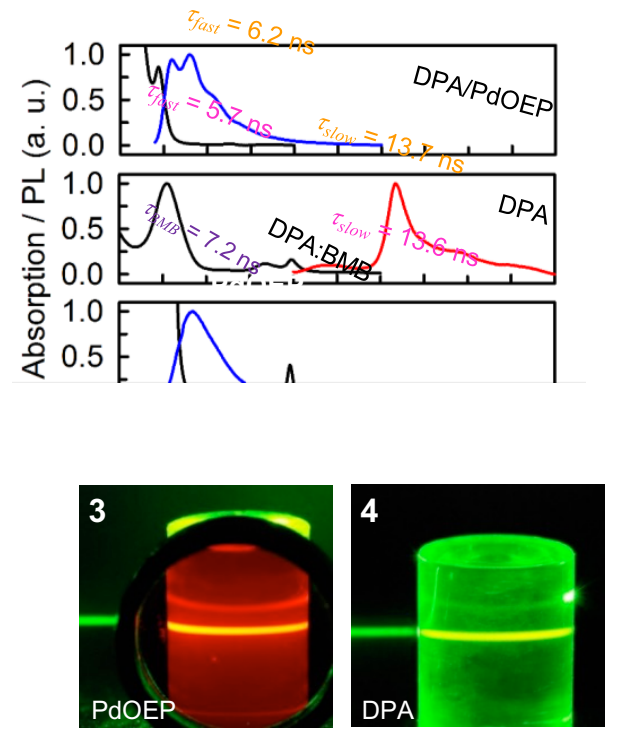

e

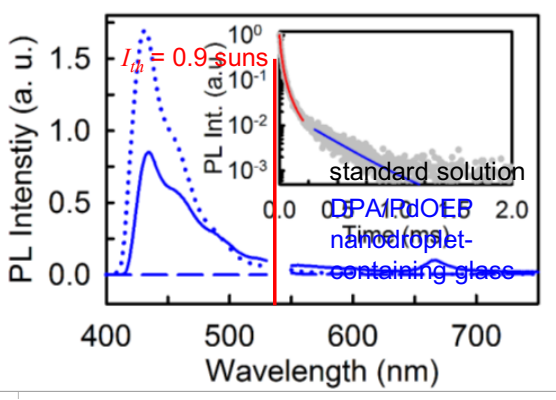

Figure 3: Optical properties of dye-doped nanodroplet-containing glassy polymers. (a) Normalized absorption (black lines) and photoluminescence (PL) spectra of nanodroplet-containing glassy polymers doped with DPA $\left(10^{-5} \mathrm{M}\right)$, PdOEP $\left(10^{-5} \mathrm{M}\right)$ or DPA/PdOEP $\left(1.5 \times 10^{-2} \mathrm{M} / 2 \times 10^{-5} \mathrm{M}\right)$ excited at $375 \mathrm{~nm}$ (DPA) or under continuous wave laser excitation at $543 \mathrm{~nm}$ (PdOEP, DPA/PdOEP). (b) Decay dynamics of the blue PL at $435 \mathrm{~nm}$ detected in the dye-doped polymer and in a reference solution of DPA $\left(10^{-2} \mathrm{M}\right)$ in BMB under pulsed laser excitation at $340 \mathrm{~nm}$. In the polymer, the PL decays in a double exponential manner with a fast and a slow component. In solution, the PL decays according to a single exponential function. (c) Pictures of the DPA/PdOEP doped polymer under $543 \mathrm{~nm}$ laser excitation in the dark (1) and under ambient light (2) showing bright blue upconverted emission. In a polymer that was only doped with PdOEP (3) red PL is observed through a $600 \mathrm{~nm}$ long-pass filter, while no PL is observed if only DPA is present (4). (d) PL spectra of the DPA/PdOEP doped polymer (solid line) as well as degassed (dotted line) and non-degassed (dashed line) BMB solutions containing the same concentration of dyes $\left(1.5 \times 10^{-2} \mathrm{M} / 2 \times 10^{-5} \mathrm{M}\right)$. The laser stray-light has been removed for clarity. The inset shows the decay of the upconverted emission from the polymer at $435 \mathrm{~nm}$ under modulated $532 \mathrm{~nm}$ excitation $\left(30 \mathrm{~mW} \mathrm{~cm}^{-2}\right)$. The red and the blue solid lines show fits of data with the analytical functions used to describe the decay dynamic at high and low densities of triplet exciton, respectively. (e) TTA-UC quantum yield ( $\left.\phi_{u c}\right)$ of the DPA/PdOEP doped nanodropletcontaining polymer (triangles) and a standard system in solution (dots) as a function of the excitation intensity. The vertical line marks the excitation intensity threshold $I_{t h}$, where $\phi_{u c}$ is half of its maximum value.

The fact that the upconversion observed in the dye doped nanodroplet-containing polymer is the result of TTA-UC was confirmed by time-resolved PL measurements (inset of Figure 3d).

Under modulated excitation, the blue PL shows the expected complex decay dynamics that 
range from the nanosecond to the millisecond time scale. As commonly observed in TTA-UC systems, in the short-time range, the upconverted light decay is fast, on account of the initially high density of emitter triplets, which enhances their annihilation rate. As a result, the TTA yield $\left(\Phi_{T T A}\right)$ in this time domain is often close to unity. Conversely, at longer times, the triplet density becomes so low that TTA is a negligible dissipation channel. Thus, in this regime the delayed emission decay follows a single exponential function, with a characteristic lifetime $\tau_{u c}$ that follows the spontaneous recombination time of DPA triplets $\tau_{T}=2 \tau_{u c .}{ }^{[55]}$ The analysis of the long-time component afforded a $\tau_{T}$ of $726 \mu \mathrm{s}$. This value is typical for DPA in organic solvents, while a much higher $\tau_{T}$ would be expected for TTA-UC in the rigid phase, where the spontaneous recombination of DPA triplets is significantly less efficient. ${ }^{[55]}$ Importantly, $\tau_{T}$ can also be used to analyze the short-time component; in this domain, the analysis of the decay dynamics results $\Phi_{T T A}=99 \%$ (see Supporting Discussion). The large value of $\tau_{T}$ and the fact that $\Phi_{T T A}$ is close to unity are features observed in DPA/PdOEP solutions, and indicate that the efficient TTA-UC occurs only in the liquid phase of the nanodropletcontaining glassy polymer. This was further evidenced by cooling the material using liquid nitrogen, which led to the disappearance of the upconverted emission and to the appearance of strong PdOEP phosphorescence, due to suppression of the TTET in the frozen solvent. As expected, subsequent thawing completely restored the upconversion ability of the material (Supporting Figures S11 and S12).

The TTA-UC quantum yield, $\Phi_{U C}$, of the DPA/PdOEP doped nanodroplet-containing glassy polymer, defined as the ratio between the numbers of emitted and absorbed photons, was first measured as function of the excitation intensity at $532 \mathrm{~nm}$, using an air-free TTA-UC standard solution $\left(\Phi_{U C}=26 \%\right)$ as reference (see Methods and Supporting Material). In order to compare the performance of the two systems, we show in Figure $3 \mathrm{e}$ the measured $\Phi_{U C}$ as function of the excitation intensity. The log-log plots of the data reveal two distinct regimes; below a threshold value the efficiency depends on the excitation power density, but at high 
excitation intensity $\Phi_{U C}$ of the DPA/PdOEP nanodroplet-containing glassy polymer is constant at $\sim 15 \%$. This behavior is common and related to the bimolecular nature of the TTA step, which makes the efficiency dependent on the density of annihilating triplets and therewith the excitation intensity. However, at a sufficiently high excitation intensity the TTA rate is much faster than the spontaneous decay of triplet states and TTA becomes their main recombination pathway with a $\Phi_{T T A}$ of $100 \%$. In this case, $\Phi_{U C}$ reaches a constant value provided that the efficiencies of the intersystem crossing, TTET, and of the emitter fluorescence remain constant. ${ }^{[3,21]}$

An instructive figure of merit is the threshold excitation intensity $I_{t h}$ where the spontaneous decay rate of the emitter triplet equals the TTA rate and thus $\Phi_{U C}$ reaches half of its maximum. ${ }^{[3,9,32,56]}$ The DPA/PdOEP nanodroplet-containing glassy polymer exhibits an $I_{t h}$ of $\sim 1.4 \mathrm{~mW} \mathrm{~cm}^{-2}$, which corresponds to $\sim 0.9$ suns (vertical line in Figure $3 \mathrm{e}$ and Supporting Figure S13). This subsolar intensity threshold matches that of the reference solution well, and corroborates that the TTA-UC process in the nanodroplet-containing polymer occurs in the liquid phase. Another important figure of merit for solar harvesting applications is $\Phi_{U C}$ at an excitation density of one solar irradiance; in the case of the DPA/PdOEP nanodropletcontaining polymer this value is $\sim 9 \%$, the highest ever reported for TTA-UC in a rigid matrix. ${ }^{[26,29]}$ Indeed, upconversion was observed when the material was excited with noncoherent green light at $543 \mathrm{~nm}$ obtained from a filtered high-pressure xenon-lamp (20-30 mW $\mathrm{cm}^{-2}$ ) or with collimated solar light passed through a $515 \mathrm{~nm}$ long-pass filter (Figure S14). Taken together, the present material concept displays characteristics that are useful for solar harvesting technologies and appears to be a promising framework for further development into stable devices, especially by replacing the model UC-dyes used here by more (photo)stable chromophores and/or the addition of stabilizers. ${ }^{[4,7]}$ 
a
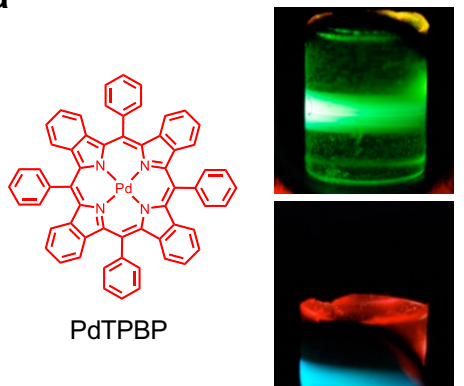

$\lambda_{\mathrm{EX}}=635 \mathrm{~nm}$

b

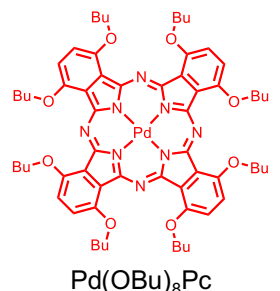

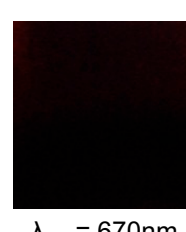

$\lambda_{\mathrm{EX}}=670 \mathrm{~nm}$
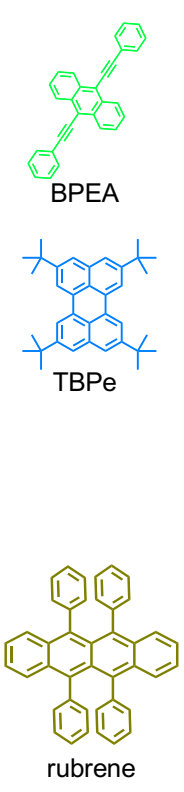

C

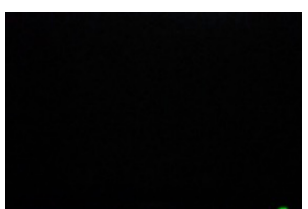

as prepared

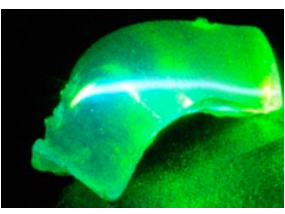

bent after heating d

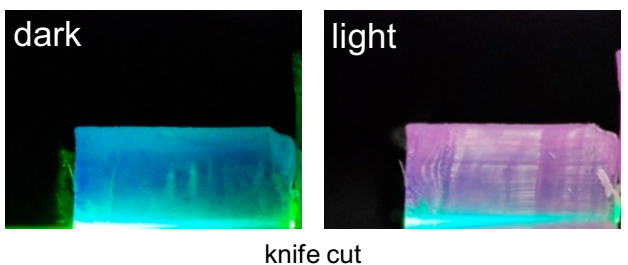

Figure 4: Tuning upconversion in nanodroplet-containing polymers. (a, b) Pictures of dye-doped nanodroplet-containing polymer glasses under laser excitation at the indicated wavelengths. The materials contain the sensitizers $\mathrm{PdTPBP}$ or $\mathrm{Pd}(\mathrm{OBu})_{8} \mathrm{Pc}$ and the emitters BPEA, TBPe, or rubrene, as indicated. (c) Pictures of a thermoplastic nanodroplet-containing polymer glass doped with DPA/PdOEP under green laser excitation, as prepared and after re-shaping at elevated temperature. (d) Pictures of a slice of a nanodroplet-containing elastomer doped with DPA/PdOEP under green excitation in dark and ambient light. Thanks to its rubbery properties, the slice could be prepared by cutting the material with a knife.

To further explore the efficiency, $\Phi_{U C}$ was measured under high excitation intensity at $532 \mathrm{~nm}$ $\left(100 \mathrm{~mW} \mathrm{~cm}^{-2}\right)$ using both an integrating sphere and a quasi-collinear PL setup for the detection of the emitted light (see Methods and Supporting Material) and averaging data collected for three independently made samples. ${ }^{[3]}$ This yielded $\Phi_{U C}$ values of $16 \pm 2 \%$ and $14 \pm 3 \%$, respectively, confirming the data shown in Figure 3e. To our best knowledge, this is by far the highest TTA-UC efficiency ever reported for a rigid polymer prepared and operated under ambient conditions. The fact that the efficiency is substantially lower than that of a degassed DPA/PdOEP reference solution in THF $\left(\Phi_{U C}=26 \%\right)$ is partially related to the reduced DPA fluorescence quantum yield in BMB (78\%) vis a vis THF (96\%) (Figure S26) and likely due to quenching/photodegradation related to some residual oxygen, suggesting room for further improvement. 
The generality and versatility of the materials design concept were demonstrated by varying several parameters. PdOEP was replaced with Pt(II) octaetylporphyrin (PtOEP), another sensitizer that can be paired with DPA. This resulted materials with a maximum green-to-blue $\Phi_{U C}$ of $\sim 8 \%$. A detailed spectroscopic study shows that the characteristics are very similar to the DPA/PdOEP-doped system (see Supporting Material). Three other dye pairs were incorporated in the nanodroplet-containing glassy polymer in order to extend the process to other spectral ranges (Figure 4a, b). The sensitizer palladium(II)-meso-tetraphenyl tetrabenzoporphine (PtTPBP) was combined with the emitters 9,10-bis(phenylethynyl) anthracene (BPEA) and tetra-tert-butylperylene (TBPe) to achieve red-to-green and red-to blue upconversion (Figure 4a), respectively. ${ }^{[2,21]}$ The integration of the sensitizer/emitter pair palladium(II)-octabutoxyphthalocyanine $\left(\mathrm{Pd}(\mathrm{OBu})_{8} \mathrm{Pc}\right)$ and rubrene afforded a material that displayed red-to-yellow upconversion with a maximum $\Phi_{U C}$ of $15 \pm 3 \%$ (Figure $4 \mathrm{~b}$ and Supporting Material). Finally, the composition and mechanical properties of the matrix were varied. A thermoplastic upconverting material that could be re-shaped upon heating above $50{ }^{\circ} \mathrm{C}$ was made by using the original recipe, but omitting the cross-linker TEG-diMA (Figure 4c). A rubbery material was made by replacing the methacrylic monomers with their acrylic counterparts, i.e., 2-hydroxyethyl acrylate, acrylic acid, and tetraethylene glycol diacrylate (Figure 4d). Other variations, such as the substitution of BMB with toluene, xylenes or 1-[(2-ethylhexyl)oxy]-4-methoxybenzene also resulted in transparent upconverting materials (Supporting Figure S16).

In summary, we have developed a simple and versatile one-step approach to create upconverting nanostructured polymers that combine the desirable and tailorable mechanical, thermal, and optical properties of polymer matrices with photophysical properties that are normally only observed in degassed solutions of upconverting dyes. The glassy polymer matrix investigated provides surprisingly good protection from atmospheric oxygen and permits operation under ambient conditions. Some of the materials made displayed record 
upconversion efficiencies under conditions that would be experienced in solar energy harvesting applications. Considering the generality of this materials design strategy, and the robustness of the morphology formation, the framework presented here appears not only to be useful for the fabrication of upconversion materials and devices, but should be exploitable to access other types of advanced optical materials.

\section{Experimental Section}

Synthesis of upconverting nanodroplet-containing glassy polymers. Chemicals were purchased from Sigma-Aldrich, ABCR, Acros Organics, TCI (Tokyo Chemical Industry Co., Ltd.) or Inochem, Ltd. (Frontier Scientific, Inc) and were used as received. All nanodropletcontaining polymers were prepared under ambient conditions without prior deoxygenation of the mixture or its single components, unless specifically stated otherwise. A $20 \mathrm{~mL}$ vial equipped with a stir bar was charged under ambient conditions with CTAB (250 mg, $5 \mathrm{wt} \%)$, HEMA (2.66 g, $53.2 \mathrm{wt} \%$ ), TEG-diMA (175 mg, $3.5 \mathrm{wt} \%$ ), BMB (500 mg, $10 \mathrm{wt} \%$ ), ethylene glycol (750 mg, $15 \mathrm{wt} \%$ ) and MAA (665 mg, $13.3 \mathrm{wt} \%$ ) (total weight: $5 \mathrm{~g}$ ). Benzoyl peroxide (10 mg, $0.2 \mathrm{wt} \%$ ) was subsequently added and the mixture was heated to $80^{\circ} \mathrm{C}$ and stirred for 10-15 min to appear clear and homogeneous, before it was filtered warm through a $0.2 \mu \mathrm{m}$ PTFE-filter into either an optical glass cuvette or a glass vial containing $N, N$-dimethyl aniline (10 mg, $0.2 \mathrm{wt} \%$ ). The still clear mixture was briefly shaken and left to stand at $20^{\circ} \mathrm{C}$ until gelation ( 10-15 min), before it was placed into a water bath $\left(15^{\circ} \mathrm{C}\right)$, which served as a cooling medium. After $\sim 30 \mathrm{~min}$, the polymerization was complete and a transparent, hard material was obtained, which was either kept in a polymer film sealed cuvette and used for quantitative optical measurements or released from the glass vial by breaking the latter with a hammer. Materials of similar appearance were also obtained when BMB was replaced with toluene, xylenes or 1-[(2-ethylhexyl)oxy]-4-methoxybenzene (EMOB).

Green-to-blue upconverting nanodroplet-containing glassy polymers were prepared by substituting the BMB with a solution of MOEP $\left(2 \times 10^{-4} \mathrm{M}\right)$ in BMB $(500 \mathrm{mg}, 10 \mathrm{wt} \%$ of total weight) and adding DPA (25 mg). Assuming a final density of $1 \mathrm{~g} \cdot \mathrm{cm}^{-3}$ for the final material, the chromophore concentrations were $2 \times 10^{-5} \mathrm{M}$ for PdOEP or PtOEP and $1.5 \times 10^{-2} \mathrm{M}$ for DPA. A reduction of the DPA concentration by a factor of 2 resulted in a virtually unchanged upconversion intensity (Supporting Figure S29). 
Red-to-blue or red-to-green upconverting nanodroplet-containing glassy polymers were prepared by using the same recipe and contained PdTPBP $\left(2 \times 10^{-5} \mathrm{M}\right)$ as sensitizer and TBPe or BPEA $\left(2 \times 10^{-3} \mathrm{M}\right)$ as emitters, respectively. The dark red-to-yellow upconverting nanodroplet-containing glassy polymers contained instead $\mathrm{Pd}(\mathrm{OBu})_{8} \mathrm{Pc}\left(10^{-5} \mathrm{M}\right)$ and rubrene $\left(10^{-3} \mathrm{M}\right)$

Material characterization. Differential scanning calorimetry measurements were performed using a Mettler-Toledo DSC-1 equipped with a Huber TC100 cooling regulation system. Small-angle X-ray scattering spectra were recorded using an SMAX3000 pinhole camera from Rigaku Innovative Technologies, Auburn Hills, USA. The $\sim 2.5 \mathrm{~mm}$ thick samples were measured in vacuum at room temperature. The scattering data is presented as a function of the momentum transfer $\mathrm{q}=4 \pi \cdot \lambda^{-1} \cdot \sin (\theta / 2)$, where $\theta$ is the scattering angle and $\lambda=0.1524 \mathrm{~nm}$ is the photon wavelength. Raw data were processed according to standard procedures. Dynamic mechanical analyses were conducted on a TA Instruments DMA Q 800 using a frequency of $1 \mathrm{~Hz}$ and a heating rate of $10{ }^{\circ} \mathrm{C} / \mathrm{min}$.

Scanning electron microscopy (SEM). The ultrastructure was investigated with a MIRA 3 LMH field-emission electron microscope (Tescan, Brno, Czech Republic). To prevent charging, the samples were sputter-coated by a thin layer of $\mathrm{Pd} / \mathrm{Pt}$ alloy $(80: 20)$ prior to imaging.

Optical measurements. UV-Vis absorption spectra were recorded on a Shimadzu UV-2401PC or on a Cary Varian 50 spectrometer. Steady-state PL spectra were acquired with a Photon Technology International C720 spectrophotometer equipped with a Hamamatsu R928P photomultiplier or with a nitrogen cooled CCD (Spex 2000) coupled to a polychromator Triax 190 from J-Horiba. Green-to-blue upconversion spectra were recorded using a $2 \mathrm{~mW}$ non-polarized $543 \mathrm{~nm}$ Helium-Neon (HeNe, $543.5 \pm 2 \mathrm{~nm}$ ) laser (Thorlabs HGR020) or a focused doubled Nd:YAG diode pumped Coherent Verdi TEM $00 \mathrm{CW}$ laser at $532 \mathrm{~nm}$ for excitation. $1 / \mathrm{e}^{2}$ beam diameters of $0.83 \mathrm{~mm}(\mathrm{HeNe})$ or $0.80 \mathrm{~mm}(\mathrm{Nd}: \mathrm{YAG})$ were measured by the knife blade method. The laser intensity has been varied using reflective power density neutral filters and measured with an optical power meter (Thorlabs PM100USB with photodiode power sensor S120VC). The excitation laser light was further cleaned by using line filters of Edmund Optics $(532 \pm 5 \mathrm{~nm})$ or Thorlabs $(543.5 \pm 10 \mathrm{~nm})$, while for detection the laser stray-light was attenuated with the corresponding Edmund Optics notch filter. For the red-to-blue, red-to-green and dark red-to-yellow upconversion, we used a $635 \mathrm{~nm}$ or a 
$670 \mathrm{~nm}$ solid-state laser diode from Roithner Lasertechnik as excitation sources. All spectra have been corrected for the instrumental optical response.

For time-resolved upconversion measurements, samples have been excited at $532 \mathrm{~nm}$ by modulating a Nd:YAG laser with a TTi TG5011 wavefunction generator. Spectra were recorded by nitrogen cooled PMT (Hamamatsu R5509-73) coupled with a high-speed amplifier (Hamamatsu C5594), a 74100 Cornestone 2601/4 (ORIEL) monochromator, and a PCI plug-in multichannel scaler ORTEC 9353 100-ps Time Digitizer/MCS in a photon counting acquisition mode. Fluorescence and phosphorescence time-resolved spectra were obtained by using the III harmonic of Nd:YAG Continuum Minilite laser (10 ns pulse width) detecting the luminescence decay by an Edinburgh LP90 Flash Photolysis Setup.

The upconversion quantum efficiency $\Phi_{U C}$ of the nanodroplet-containing polymers was determined relative to the maximum upconversion quantum yield of the DPA/PtOEP UC pair in deaerated tetrahydrofuran $\left([\mathrm{DPA}]=10^{-2} \mathrm{M},[\mathrm{PtOEP}]=10^{-4} \mathrm{M}\right)$ used as secondary standard in quasi-collinear and integrating sphere PL setups. This method has practical advantages over using a primary standard and is an accepted practice in the field. ${ }^{[28,55,57]}$ The theoretical maximum UC quantum efficiency is 0.50 , since the TTA-UC process uses two low energy photons to produce one high-energy photon. The maximum $\Phi_{U C}$ of the secondary standard is 0.26 , under excitation at $532 \mathrm{~nm}$ and a power density of $100 \mathrm{~mW} \mathrm{~cm}^{-2}$; it was measured and calculated by using the laser dye Rhodamine $6 \mathrm{G}\left(10^{-5} \mathrm{M}\right.$ in ethanol) as reference material. ${ }^{[3]}$ The recorded spectra have been corrected for the setup optical response. The secondary standard (or "reference") solution was freshly prepared in a glovebox under nitrogen atmosphere $\left(\mathrm{O}_{2}\right.$-level $\left.<0.1 \mathrm{ppm}\right)$ and the cuvette was sealed with a hot melt adhesive before being characterized prior to each set of measurements outside of the glovebox. To confirm the results obtained, $\Phi_{U C}$ measurements have also been performed using an integrating sphere on a series of independently made samples (see Supporting Methods for further details). ${ }^{[37]}$

Received and accepted dates 


\section{Supporting Information}

Supporting Information is available from the Wiley Online Library or from the author.

\section{Acknowledgements}

The authors are grateful for the financial support of the Swiss National Science Foundation SNSF (project numbers 135405 and 152968) and the Adolphe Merkle Foundation. We thank Dr. Sandor Balog for help with the small-angle X-ray scattering experiments, and Dr. Dimitri Vanhecke, Dr. David C. Thévenaz, and Dr. Mathieu A. Ayer for valuable discussions. R.V. acknowledges support from SNSF (Grant P2FRP2_165176). A. M. acknowledges support from Università Milano Bicocca (Grant No. 2016-ATESP-0052 and Cariplo Foundation (Grant No. 2016-0925).

Correspondence and requests for materials should be addressed to Christoph Weder or Yoan C. Simon. (E-mail: christoph.weder@unifr.ch, yoan.simon@usm.edu).

Received: ((will be filled in by the editorial staff))

Revised: ((will be filled in by the editorial staff)) Published online: ((will be filled in by the editorial staff)) 


\section{References}

[1] C. A. Parker, C. G. Hatchard, T. A. Joyce, Nature 1965, 205, 1282.

[2] T. N. Singh-Rachford, F. N. Castellano, Coord. Chem. Rev. 2010, 254, 2560.

[3] A. Monguzzi, R. Tubino, S. Hoseinkhani, M. Campione, F. Meinardi, Phys. Chem. Chem. Phys. 2012, 14, 4322.

[4] Y. C. Simon, C. Weder, J. Mater. Chem. 2012, 22, 20817.

[5] J. C. Goldschmidt, S. Fischer, Adv. Optical Mater. 2015, 3, 510.

[6] A. Monguzzi, F. Bianchi, A. Bianchi, M. Mauri, R. Simonutti, R. Ruffo, R. Tubino, F. Meinardi, Adv. Energy Mater. 2013, 3, 680.

[7] A. J. Svagan, D. Busko, Y. Avlasevich, G. Glasser, S. Baluschev, K. Landfester, ACS Nano 2014, 8, 8198.

[8] R. Vadrucci, C. Weder, Y. C. Simon, Mater. Horiz. 2015, 2, 120.

[9] M. Wu, D. N. Congreve, M. W. B. Wilson, J. Jean, N. Geva, M. Welborn, T. Van Voorhis, V. Bulović, M. G. Bawendi, M. A. Baldo, Nat Photon 2016, 10, 31.

[10] C. E. McCusker, F. N. Castellano, Top. Curr. Chem. 2016, 374, 1.

[11] M. A. Filatov, S. Baluschev, K. Landfester, Chem. Soc. Rev. 2016, 45, 4668.

[12] C. Wohnhaas, K. Friedemann, D. Busko, K. Landfester, S. Baluschev, D. Crespy, A. Turshatov, ACS Macro Lett. 2013, 2, 446.

[13] P. Duan, N. Yanai, N. Kimizuka, J. Am. Chem. Soc. 2013, 135, 19056.

[14] H. Kouno, T. Ogawa, S. Amemori, P. Mahato, N. Yanai, N. Kimizuka, Chem. Sci. 2016, 7, 5224.

[15] V. Gray, D. Dzebo, M. Abrahamsson, B. Albinsson, K. Moth-Poulsen, Phys. Chem. Chem. Phys. 2014, 16, 10345.

[16] C. Ye, B. Wang, R. Hao, X. Wang, P. Ding, X. Tao, Z. Chen, Z. Liang, Y. Zhou, J. Mater. Chem. C 2014, 2, 8507.

[17] R. R. Islangulov, J. Lott, C. Weder, F. N. Castellano, J. Am. Chem. Soc. 2007, 129, 12652.

[18] F. N. Castellano, T. N. Singh-Rachford, Inorg. Chem. 2009, 48, 2541.

[19] K. Sripathy, R. W. MacQueen, J. R. Peterson, Y. Y. Cheng, M. Dvorak, D. R. McCamey, N. D. Treat, N. Stingelin, T. W. Schmidt, J. Mater. Chem. C 2015, 3, 616.

[20] Y. Murakami, Y. Himuro, T. Ito, R. Morita, K. Niimi, N. Kiyoyanagi, J. Phys. Chem. $B$ 2016, 120, 748 .

[21] P. Duan, N. Yanai, H. Nagatomi, N. Kimizuka, J. Am. Chem. Soc. 2015, 137, 1887.

[22] M. Haering, R. Perez-Ruiz, A. Jacobi von Wangelin, D. Diaz, Chem. Commun. 2015, $51,16848$.

[23] R. Vadrucci, C. Weder, Y. C. Simon, J. Mater. Chem. C 2014, 2, 2837.

[24] P. B. Merkel, J. P. Dinnocenzo, J. Lumin. 2009, 129, 303.

[25] S. H. Lee, M. A. Ayer, R. Vadrucci, C. Weder, Y. C. Simon, Polym. Chem. 2014, 5, 6898.

[26] M. Oldenburg, A. Turshatov, D. Busko, S. Wollgarten, M. Adams, N. Baroni, A. Welle, E. Redel, C. Wöll, B. S. Richards, I. A. Howard, Adv. Mater. 2016, $28,8477$.

[27] S. Amemori, Y. Sasaki, N. Yanai, N. Kimizuka, J. Am. Chem. Soc. 2016, 138, 8702.

[28] T. Ogawa, N. Yanai, A. Monguzzi, N. Kimizuka, Sci. Rep. 2015, 5, 10882.

[29] A. Turshatov, D. Busko, N. Kiseleva, S. L. Grage, I. A. Howard, B. S. Richards, ACS Appl. Mater. Interfaces 2017.

[30] R. S. Khnayzer, J. Blumhoff, J. A. Harrington, A. Haefele, F. Deng, F. N. Castellano, Chem. Commun. 2012, 48, 209.

[31] K. Xu, J. Zhao, D. Escudero, Z. Mahmood, D. Jacquemin, J. Phys. Chem. C 2015, $119,23801$.

[32] S. Hoseinkhani, R. Tubino, F. Meinardi, A. Monguzzi, Phys. Chem. Chem. Phys. 2015, 17, 4020 . 
[33] A. Turshatov, D. Busko, S. Baluschev, T. Miteva, K. Landfester, New J. Phys. 2011, 13, 083035.

[34] C. Mongin, J. H. Golden, F. N. Castellano, ACS Appl. Mater. Interfaces 2016.

[35] A. Monguzzi, M. Frigoli, C. Larpent, R. Tubino, F. Meinardi, Adv. Funct. Mater. 2012, 22, 139.

[36] Y. C. Simon, S. Bai, M. K. Sing, H. Dietsch, M. Achermann, C. Weder, Macromol. Rapid Commun. 2012, 33, 498.

[37] D. C. Thevenaz, A. Monguzzi, D. Vanhecke, R. Vadrucci, F. Meinardi, Y. C. Simon, C. Weder, Mater. Horiz. 2016, 3, 602.

[38] D. C. Thévenaz, S. H. Lee, F. Guignard, S. Balog, M. Lattuada, C. Weder, Y. C. Simon, Macromol. Rapid Commun. 2016, 37, 826.

[39] C. Wohnhaas, A. Turshatov, V. Mailänder, S. Lorenz, S. Baluschev, T. Miteva, K. Landfester, Macromol. Biosci. 2011, 11, 772.

[40] Q. Liu, B. Yin, T. Yang, Y. Yang, Z. Shen, P. Yao, F. Li, J. Am. Chem. Soc. 2013, $135,5029$.

[41] J.-H. Kang, E. Reichmanis, Angew. Chem. Int. Ed. 2012, 51, 11841.

[42] O. S. Kwon, J.-H. Kim, J. K. Cho, J.-H. Kim, ACS Appl. Mater. Interfaces 2014, 7, 318.

[43] S. M. Borisov, C. Larndorfer, I. Klimant, Adv. Funct. Mater. 2012, 22, 4360.

[44] D. L. Gin, W. Gu, B. A. Pindzola, W.-J. Zhou, Acc. Chem. Res. 2001, 34, 973.

[45] M. Seo, M. A. Hillmyer, Science 2012, 336, 1422.

[46] M. W. Schulze, L. D. McIntosh, M. A. Hillmyer, T. P. Lodge, Nano Lett. 2014, 14, 122.

[47] C. L. Lester, S. M. Smith, C. D. Colson, C. A. Guymon, Chem. Mater. 2003, 15, 3376.

[48] D. B. Papkovsky, T. C. O’Riordan, J. Fluoresc. 2005, 15, 569.

[49] J. S. Lissau, D. Nauroozi, M.-P. Santoni, T. Edvinsson, S. Ott, J. M. Gardner, A. Morandeira, J. Phys. Chem. C 2015, 119, 4550.

[50] J.-M. Aubry, C. Pierlot, J. Rigaudy, R. Schmidt, Acc. Chem. Res. 2003, 36, 668.

[51] F. Marsico, A. Turshatov, R. Peköz, Y. Avlasevich, M. Wagner, K. Weber, D. Donadio, K. Landfester, S. Baluschev, F. R. Wurm, J. Am. Chem. Soc. 2014, 136, 11057.

[52] J.-H. Kang, S. S. Lee, J. Guerrero, A. Fernandez-Nieves, S.-H. Kim, E. Reichmanis, Adv. Mater. 2017, 1606830.

[53] Y. Murakami, Chem. Phys. Lett. 2011, 516, 56.

[54] S. Hisamitsu, N. Yanai, N. Kimizuka, Angew. Chem. Int. Ed. 2015, 54, 11550.

[55] A. Monguzzi, M. Mauri, M. Frigoli, J. Pedrini, R. Simonutti, C. Larpent, G. Vaccaro, M. Sassi, F. Meinardi, J. Phys. Chem. Lett. 2016, 2779.

[56] A. Monguzzi, J. Mezyk, F. Scotognella, R. Tubino, F. Meinardi, Phys. Rev. B 2008, 78, 195112.

[57] A. Monguzzi, M. Mauri, A. Bianchi, M. K. Dibbanti, R. Simonutti, F. Meinardi, J. Phys. Chem. C 2016, 120, 2609. 
Copyright WILEY-VCH Verlag GmbH \& Co. KGaA, 69469 Weinheim, Germany, 2016.

\section{Supporting Information}

\section{Nanodroplet-Containing Polymers for Efficient Low-Power Light Upconversion}

Roberto Vadrucci, Angelo Monguzzi, Felipe Saenz, Bodo D. Wilts, Yoan C. Simon*, and Christoph Weder*

Table of Contents:

1. Supporting Data S2

2. Supporting Experimental Section S16

3. Supporting Discussion S22

4. Supporting Movie S30

5. Supporting References $\mathrm{S} 30$ 


\section{Supporting Data}

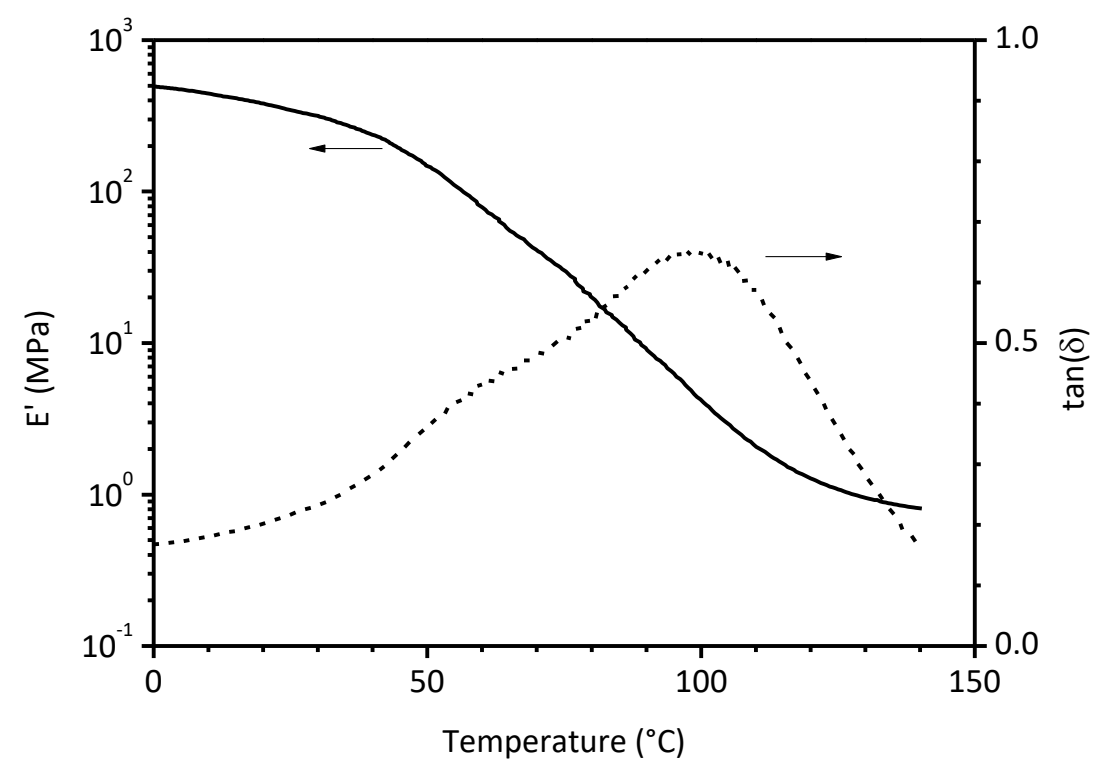

Figure S1: Dynamic mechanical thermal analysis (DMTA) of a dye-free ethylene glycol plasticized poly(HEMA-co-MAA-co-TEG-diMA)/BMB nanodroplet-containing glassy polymer film. At $25^{\circ} \mathrm{C}$, a tensile storage modulus of $\mathrm{E}^{\prime}=370 \pm 27 \mathrm{MPa}$ was obtained and the loss tangent $\left(\tan (\delta)\right.$, dashed line) displayed two local maxima at $50-60{ }^{\circ} \mathrm{C}$ and at $99^{\circ} \mathrm{C}$ (three samples average). The film samples were prepared in a glovebox under air-free conditions. The tensile storage modulus $E$ ' is comparable to the value observed for poly(2-hydroxyethyl methacrylate) containing $15 \mathrm{vol} \%$ of ethylene glycol. ${ }^{[1]}$ The two local maxima observed in the $\tan (\delta)$ trace also seem to correspond to the glass transition temperatures obtained for the nanodroplet-containing polymer with and without ethylene glycol plasticizer, respectively (Figure S22 and Supporting Discussion). 

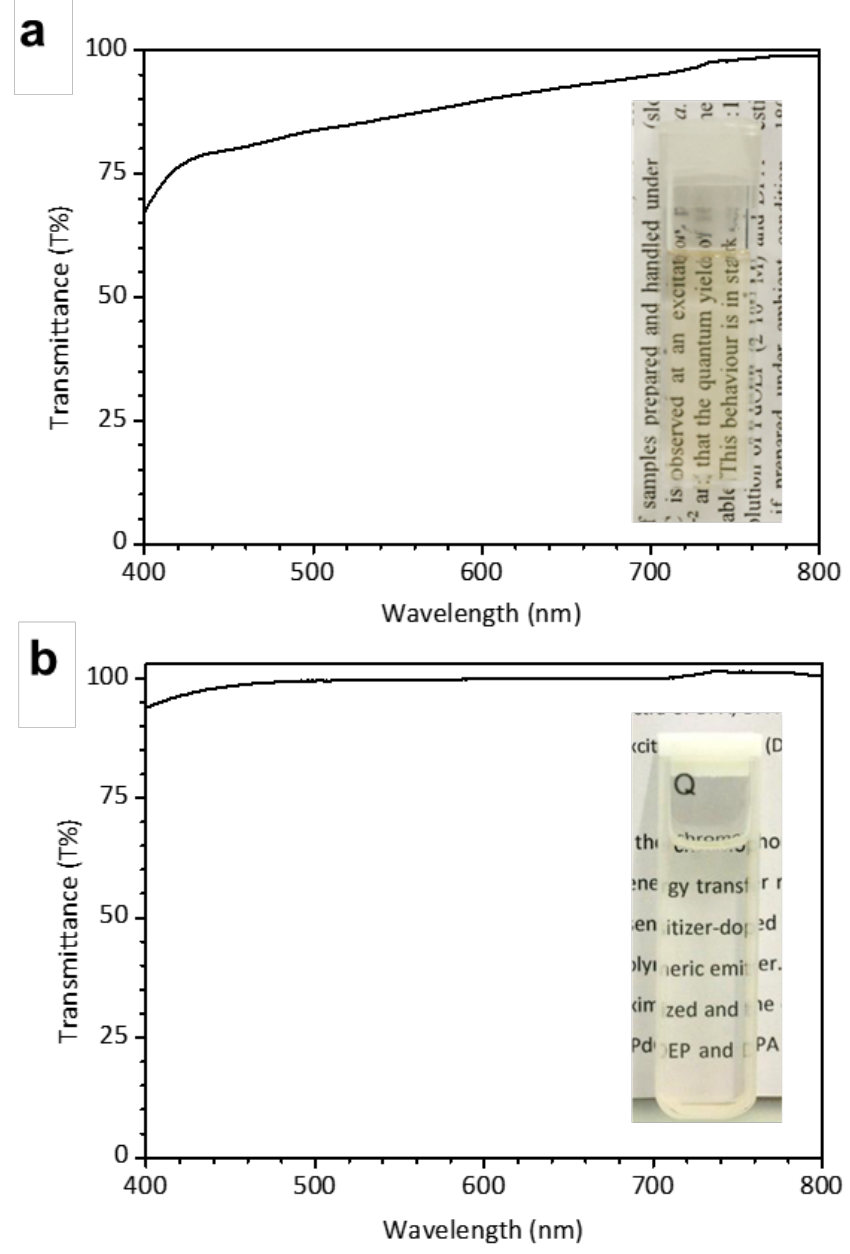

Figure S2: Transmission spectra and pictures of dye-free ethylene glycol plasticized poly(HEMA-co-MAA-co-TEG-diMA)/BMB (nanodroplet-containing glassy polymer). For the polymerized samples (a), the transmittance at typical laser-wavelengths was found to be $\sim 86 \%$ at $533 \mathrm{~nm} / 543 \mathrm{~nm}$ and $\sim 92 \%$ at $635 \mathrm{~nm} / 670 \mathrm{~nm}$. The non-polymerized mixture obtained without redoxinitiators (b) displayed a transmission of $>95.5 \%$ at wavelengths longer than $415 \mathrm{~nm}$. This mixture had the same composition as the nanophase-separated material in (a), but the redox-initiator pair benzoyl peroxide and $N, N$-dimethylaniline was omitted. The faint yellow color observed in (a) is likely to be related to oxidative decomposition of the aniline-based initiator during or after polymerization. Samples prepared in the glovebox did not display any yellowing even after several months. The reduced transmittance after polymerization suggests that the polymerization reaction induces a change of the morphology and/or of the refractive index contrast between the phases. 
a

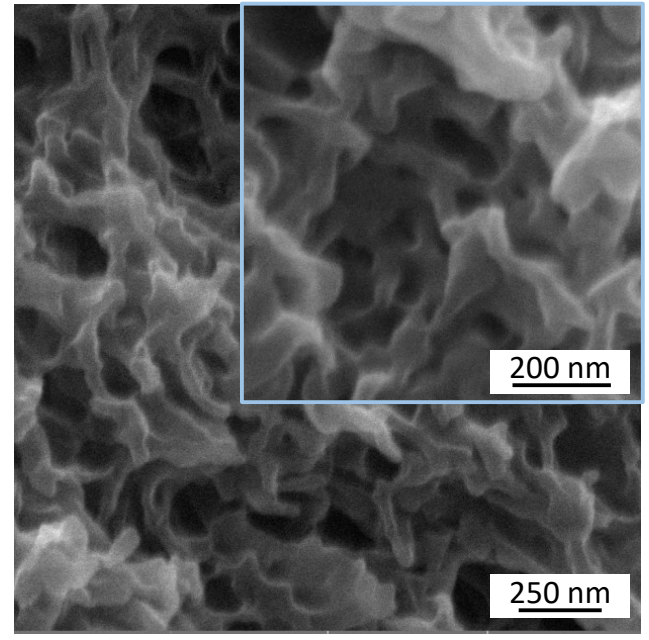

b

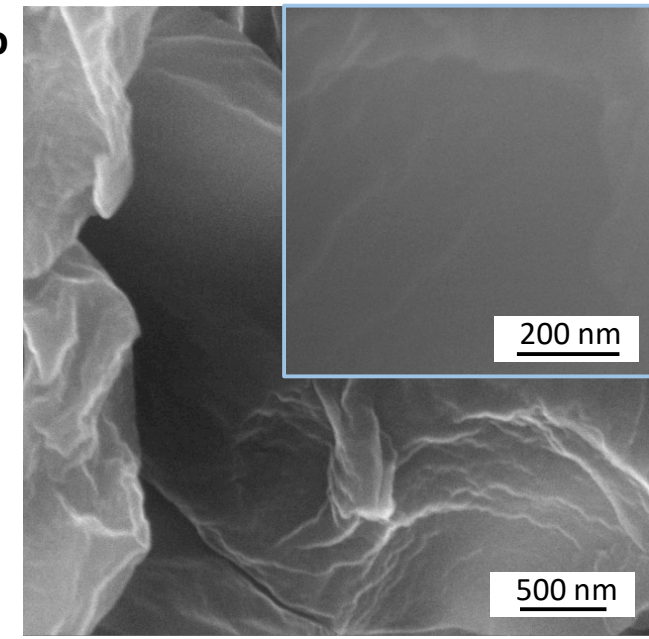

Figure S3: Scanning electron microscopy (SEM) images of a nanodroplet-containing glassy polymer doped with DPA/PdOEP and a glassy polymer prepared without the CTAB surfactant. Images were obtained after fracturing samples and sputter-coating them with $\mathrm{Pt} / \mathrm{Pd}$ alloy $(80: 20)$ to prevent charging. The dye-doped nanodroplet-containing polymer glass (a) shows a similar morphology as the dye-free reference polymer (Figure 2d). (b) In contrast to samples with CTABsurfactant (Figure 2d, S3a), no nanostructuring could be observed in materials prepared without surfactant. The insets are a magnification of a portion of panel (a) or (b), respectively. 


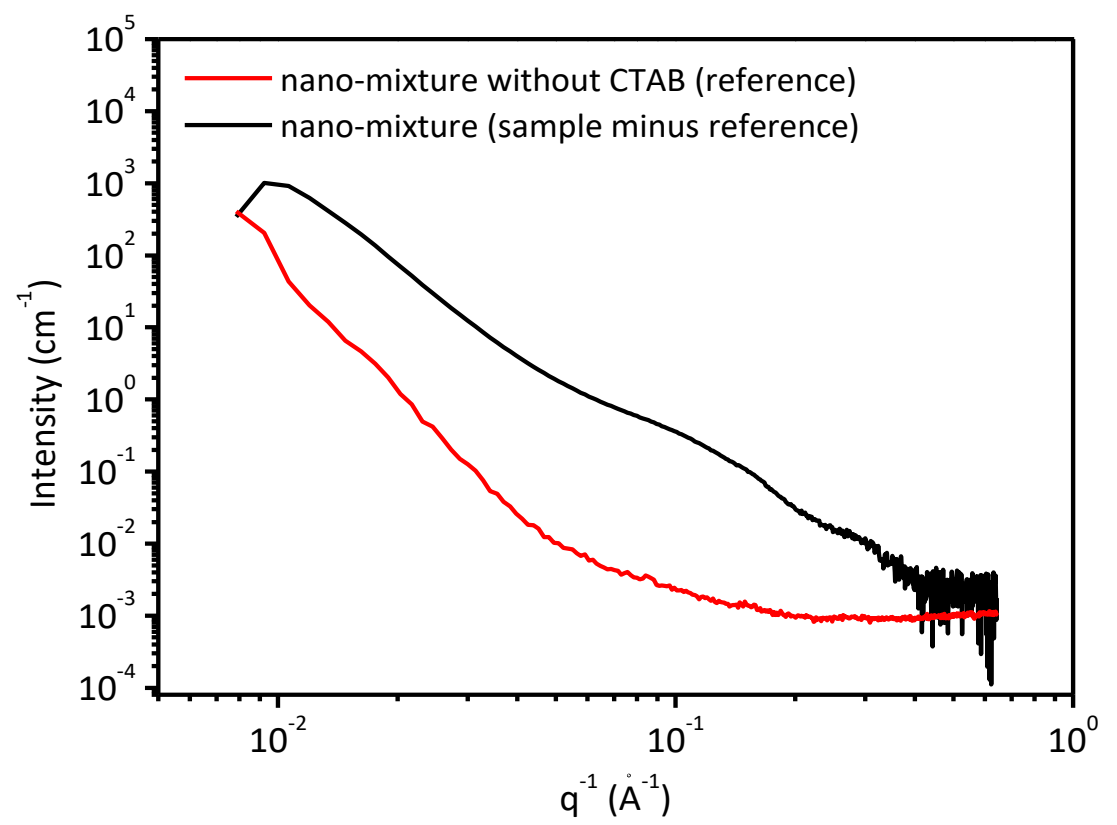

Figure S4: Small angle X-ray scattering (SAXS) data of nanodroplet-containing glassy polymer doped with DPA/PdOEP. The concentrations of DPA and PdOEP were $1.5 \times 10^{-2} \mathrm{M}$ and $2 \times 10^{-5} \mathrm{M}$, respectively. The graph depicts the data recorded for a reference DPA/PdOEP containing sample that was made without the CTAB surfactant (reference, red line), and a difference spectrum obtained by subtracting the reference from the raw data obtained on the DPA/PdOEP doped nanodropletcontaining glassy polymer prepared with CTAB. The comparison shows the presence of a nanoscale morphology in the bulk of the nanodroplet-containing glass prepared with the surfactant. 

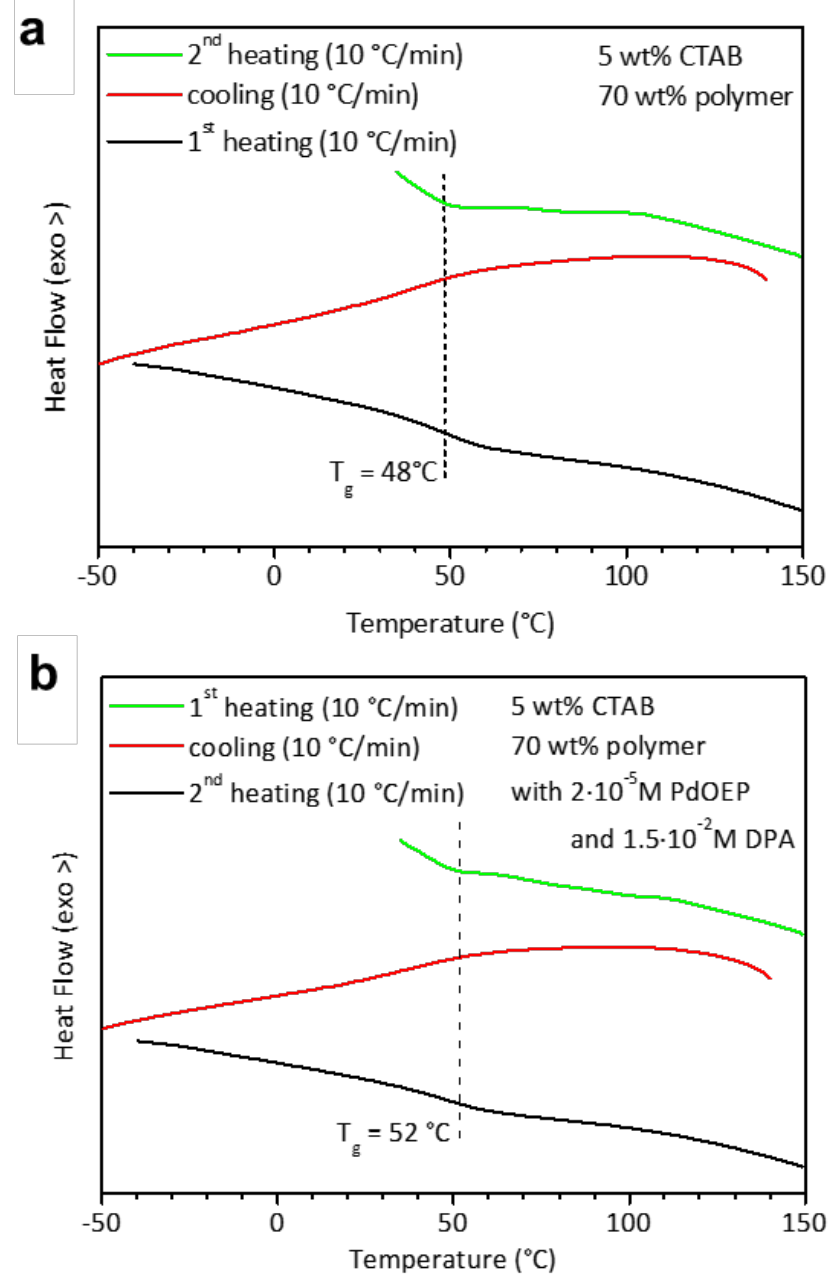

Figure S5: Differential scanning calorimetric (DSC) scans of nanodroplet-containing glassy polymers. (a) Dye-free and (b) DPA/PdOEP containing sample. Except for the chromophores, the materials have the same composition, were prepared using identical preparation procedures and also show a very similar glass transition $T_{g}\left(48{ }^{\circ} \mathrm{C}\right.$ and $52{ }^{\circ} \mathrm{C}$, respectively, recorded during the second heating cycle). The $T_{g}$ displayed by the materials can be rationalized with data found in the literature and is further explained in the Supporting discussion. ${ }^{[2,3]}$ 


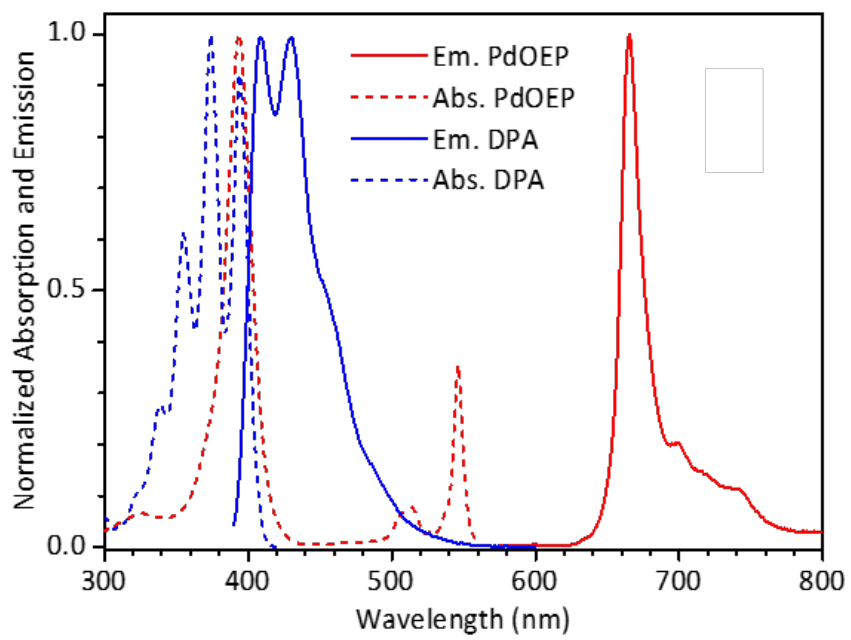

Figure S6: Normalized absorption (dotted line) and emission spectra (full line) of solutions of PdOEP $\left(10^{-5} \mathrm{M}\right.$, red) and DPA $\left(\mathbf{1 0}^{-5} \mathrm{M}\right.$, blue $)$ in BMB. In order to monitor the phosphorescence, BMB solutions containing PdOEP were degassed by sparging with argon for $30 \mathrm{~min}$ and excited at $543 \mathrm{~nm}$ with a power density of $\sim 250 \mathrm{~mW} \cdot \mathrm{cm}^{-2}$. Samples containing DPA were excited at $375 \mathrm{~nm}$ with a xenon lamp.

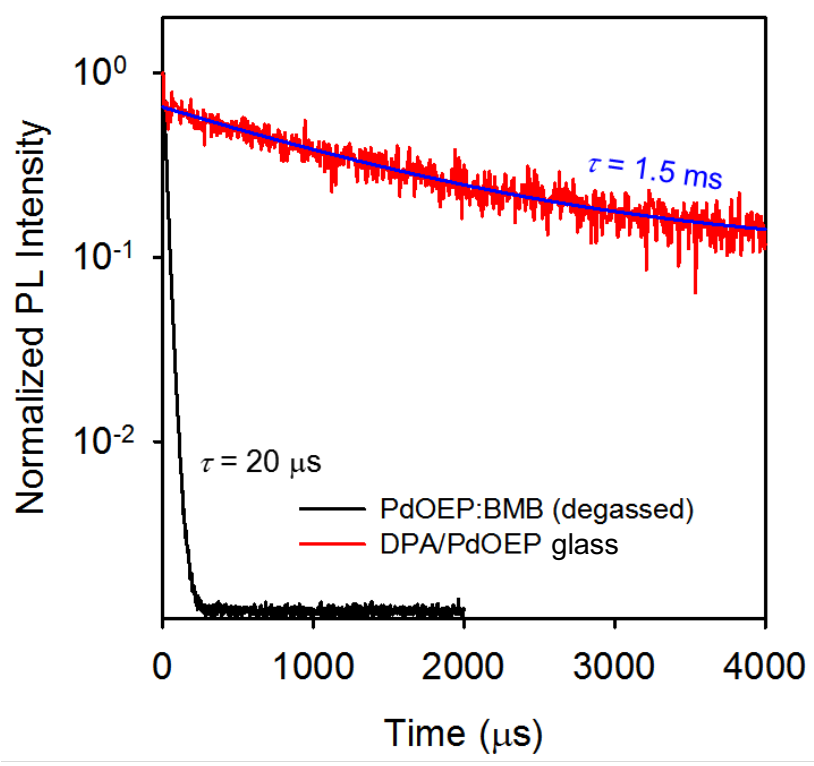

Figure S7: Normalized decay of PdOEP phosphorescence. A degassed solution containing PdOEP $\left(10^{-5} \mathrm{M}\right)$ in BMB was excited with a $355 \mathrm{~nm}$ pulsed laser. The PL signal (black line) decays as a single exponential function with a characteristic time of $\tau=20 \mu \mathrm{s}$. In the nanodroplet-containing glassy polymer doped with DPA/PdOEP, the weak residual phosphorescence from PdOEP (red line) decays as single exponential function much more slowly, with a $\tau=1.50 \mathrm{~ms}$ (blue line), suggesting that a small portion of non-interacting sensitizers is embedded in the rigid phase of the material. 


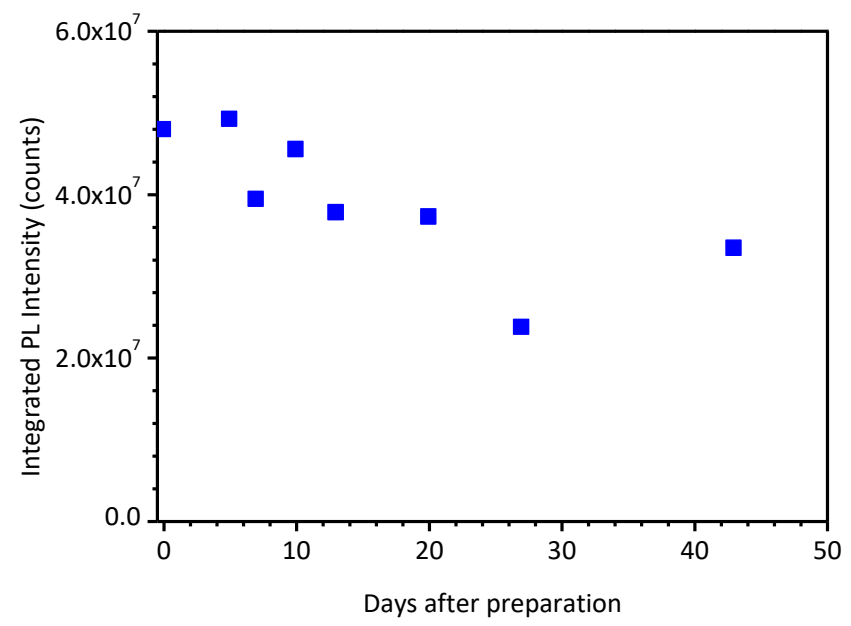

Figure S8: Shelf life photostability measurement of a DPA/PdOEP doped nanodropletcontaining glassy polymer. The graph displays the evolution over time of the integrated upconversion emission intensity of a sample irradiated at $543 \mathrm{~nm}$ with $180 \mathrm{~mW} \mathrm{~cm}^{-2}$. The sample was prepared under ambient conditions and kept sealed in a glass cuvette in the dark.

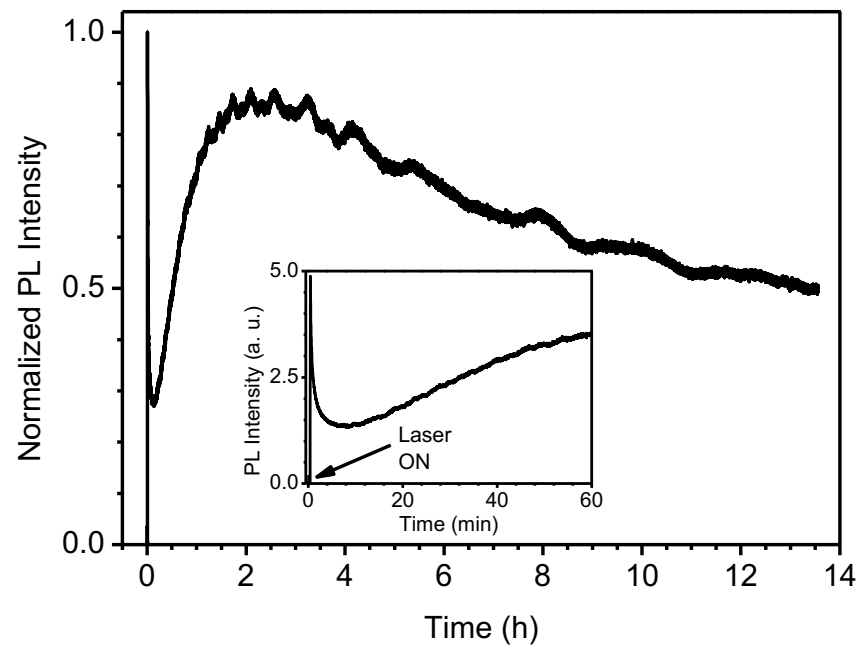

Figure S9: Photostability measurement under continuous wave irradiation of a DPA/PdOEP doped nanodroplet-containing glassy polymer. The upconversion emission intensity of the sample

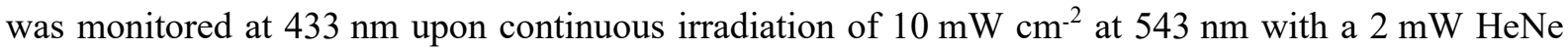
laser. Upconversion intensity decayed to $86 \%, 73 \%, 58 \%$ and $50 \%$ of the maximum intensity after 2 , 5, 10 and $13.5 \mathrm{~h}$, respectively. Inset: Upconversion intensity decay and recovery behaviour during the first 60 min of irradiation. In the first few seconds, the TTA-UC reaches maximum and rapidly decays, in order to recover to $100 \%$ during the following $2 \mathrm{~h}$. 


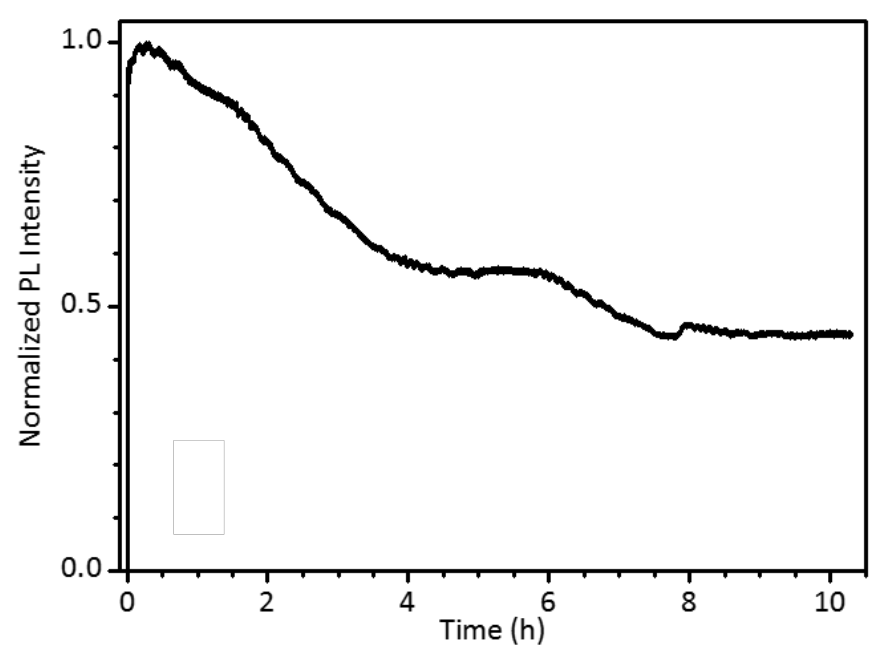

Figure S10: Photostability measurement under continuous wave irradiation of the DPA/PdOEP doped nanodroplet-containing glassy polymer prepared under air-free conditions. The upconversion emission intensity of the sample was monitored at $433 \mathrm{~nm}$ upon continuous irradiation of $10 \mathrm{~mW} \mathrm{~cm}^{-2}$ using a $2 \mathrm{~mW}, 543 \mathrm{~nm} \mathrm{HeNe}$ laser. A decay to $81 \%, 56 \%$ and $44 \%$ of the maximum intensity after 2,5 and $10 \mathrm{~h}$, respectively was observed. In comparison to the sample prepared and operated under ambient conditions (Figure S9), the maximum TTA-UC intensity was reached more quickly. This result suggests that the much slower increase of the upconversion intensity observed in Figure S9 is due to residual oxygen present in the material after preparation and indicates that this oxygen is slowly removed through photooxidation upon irradiation. 

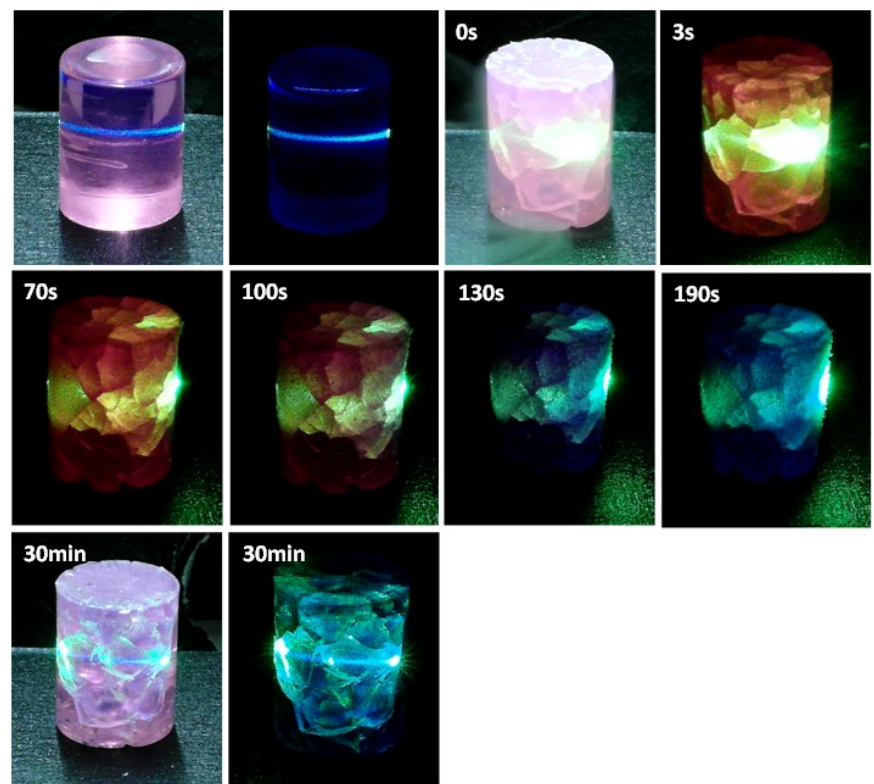

Figure S11: Green-to-blue upconverting DPA/PdOEP doped nanodroplet-containing glassy polymer in liquid nitrogen. Picture series of a green-to-blue upconverting sample before and after cooling by placement in liquid-nitrogen. Samples were excited with a $2 \mathrm{~mW}, 543 \mathrm{~nm} H e N e$ laser at a power density of $\sim 275 \mathrm{~mW} \mathrm{~cm}^{-2}$. Cooling suppresses TTA-UC and leads to the appearance of PdOEPphosphorescence due to the inefficient TTET in the frozen liquid nanophase. Equilibration of the thermally-cracked glass to ambient temperature makes the blue emission reappear.
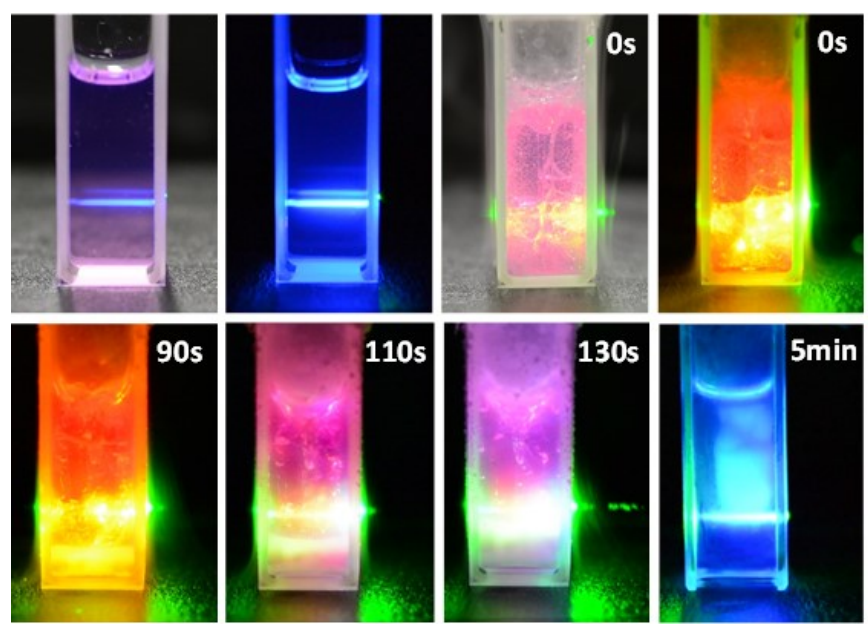

Figure S12: Argon-degassed BMB-solution containing PdOEP $\left(2 \times 10^{-5} \mathrm{M}\right)$ and DPA $\left(1.5 \times 10^{-2} \mathrm{M}\right)$ in liquid nitrogen. Picture series of a green-to-blue upconverting sample before and after cooling by placement in liquid-nitrogen. Samples were excited with a $2 \mathrm{~mW}, 543 \mathrm{~nm} H \mathrm{HeNe}$ laser at a power density of $\sim 275 \mathrm{~mW} \mathrm{~cm}^{-2}$. Cooling suppresses TTA-UC and leads to the appearance of PdOEPphosphorescence. Equilibration of the solution to ambient temperature makes the blue emission reappear. 


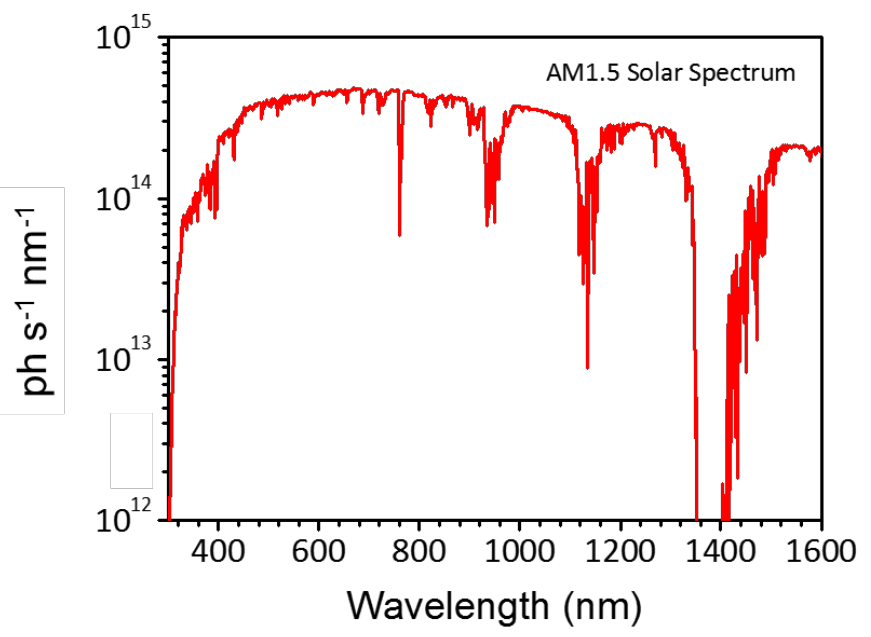

Figure S13: Solar spectrum irradiance under AM1.5 conditions. The power densities in $\mathrm{mW} \mathrm{cm} \mathrm{cm}^{-2}$ are converted to suns by relating them to the solar irradiance absorbed by the system under AM1.5 condition. The effective excitation intensity has been calculated by taking into account the integrated absorption spectrum for the most intense peak in the porphyrinic ring $Q$-band, by considering an optical path of $0.1 \mathrm{~cm}$ and sensitizer concentrations suitable to have the same absorption intensity at the maximum of the band. ${ }^{[4]}$ 

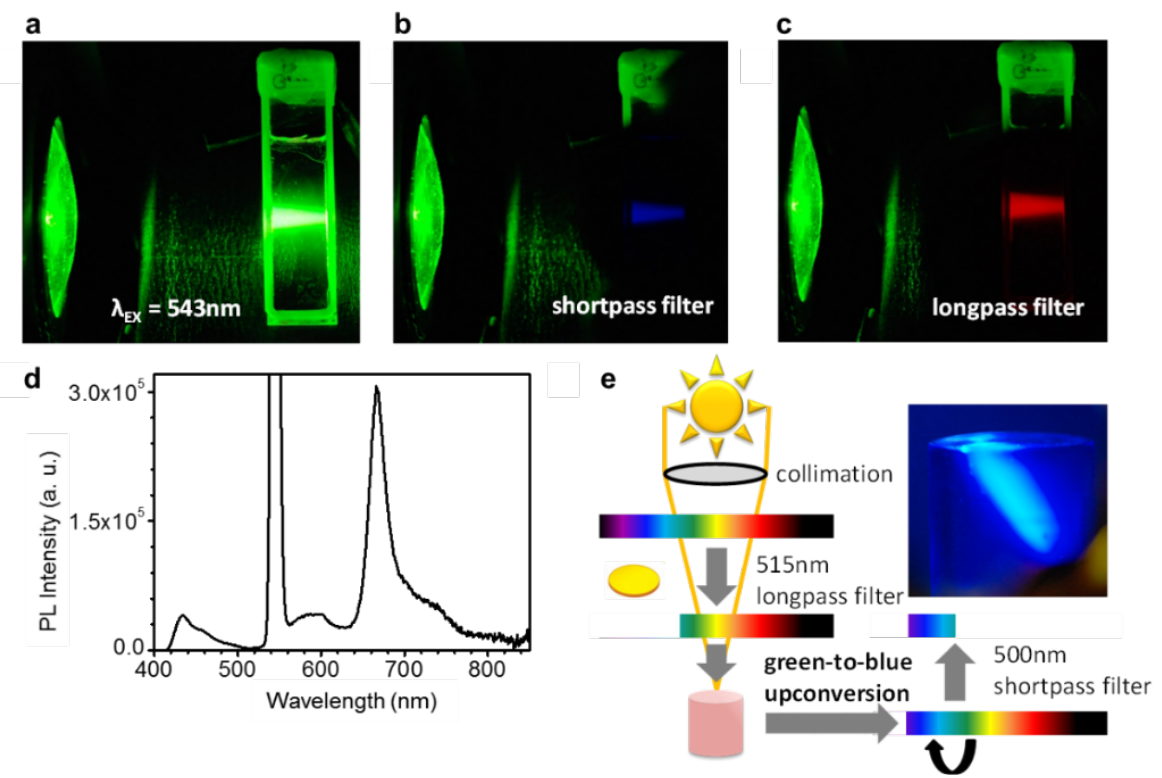

Figure S14: Pictures of green-to-blue upconverting DPA/PdOEP doped nanodroplet-containing glassy polymer excited with incoherent light. The sample was excited at $543 \mathrm{~nm}$ using a xenon lamp and a $543 \pm 10 \mathrm{~nm}$ laser-line filter $\left(0.6 \mathrm{~mW}, \sim 20-30 \mathrm{~mW} \mathrm{~cm}^{-2}\right)$, (a) seen without, (b) seen through a $500 \mathrm{~nm}$ short-pass filter and (c) seen through a $600 \mathrm{~nm}$ long-pass filter. (d) Emission spectrum of the sample displayed up- as well as downconverted light. (e) Block of the upconverting material excited with concentrated solar light longer than $515 \mathrm{~nm}$.

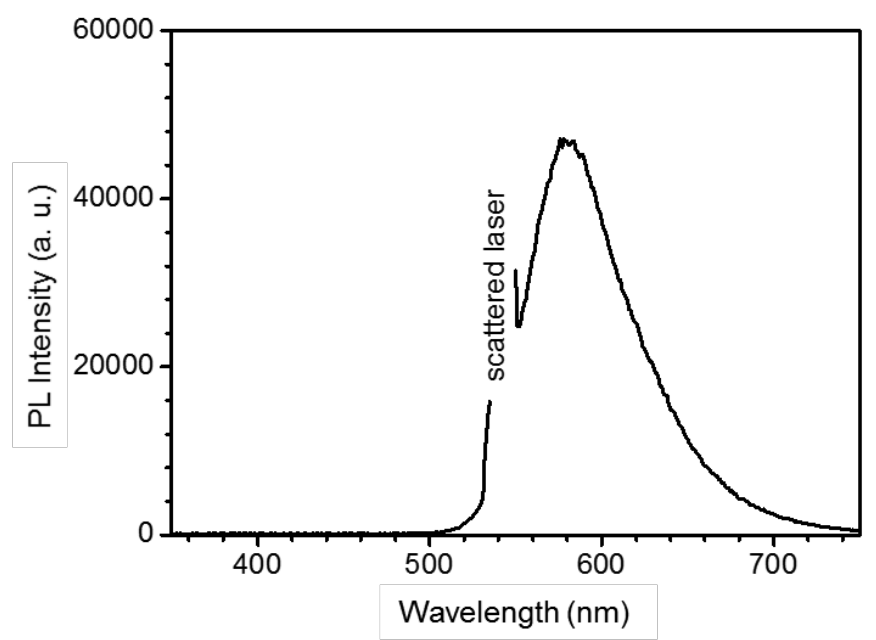

Figure S15: Emission spectrum of a dye-free nanodroplet-containing glassy polymer upon irradiation at $543 \mathrm{~nm}\left(235 \mathrm{~mW} \mathbf{c m}^{-2}\right)$. Besides the scattered laser light, the sample also shows a weak yellow emission centred at $578 \mathrm{~nm}$. A slight yellow hue was also observed in samples containing only DPA $\left(1.5 \times 10^{-2} \mathrm{M}\right.$, Figure $\left.3 \mathrm{c}-4\right)$ or PdOEP $\left(2 \times 10^{-5} \mathrm{M}\right.$, Figure $\left.3 \mathrm{c}-3\right)$. Therefore, it is assumed that the yellow emission originates from side products formed during polymerization. 

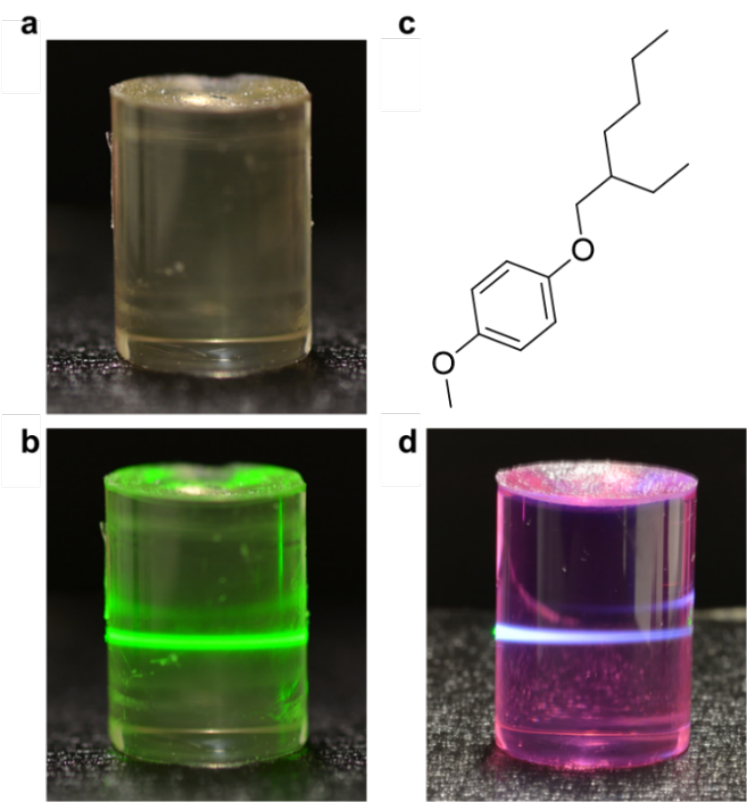

Figure S16: Pictures of ethylene glycol plasticized poly(HEMA-co-MAA-co-TEG-diMA)/1-[(2ethylhexyl)oxy]-4-methoxybenzene (EMOB) nanodroplet-containing glassy polymer. (a,b) Pictures of sample without added dyes under (a) ambient illumination or (b) irradiated with a $543 \mathrm{~nm}$ green HeNe laser. (c) Chemical structure of EMOB. (d) Picture of a green-to-blue upconverting material containing DPA $\left(1.5 \times 10^{-2} \mathrm{M}\right)$ and PdOEP $\left(2 \times 10^{-5} \mathrm{M}\right)$, irradiated at $543 \mathrm{~nm}$ with a power density of $\sim 250 \mathrm{~mW} \mathrm{~cm}{ }^{-2}$. Using semi-volatile EMOB $\left(T_{b p}=303{ }^{\circ} \mathrm{C}\right)$ instead of BMB $\left(T_{b p}=205^{\circ} \mathrm{C}\right)$ as the hydrophobic, liquid phase affords also transparent and upconverting polymer materials, presumably due an almost identical refractive index of BMB $\left(1.496 \eta_{\mathrm{D}}{ }^{20}\right)^{[5]}$ and EMOB $\left(1.496 \eta_{\mathrm{D}}{ }^{20}\right)$. 


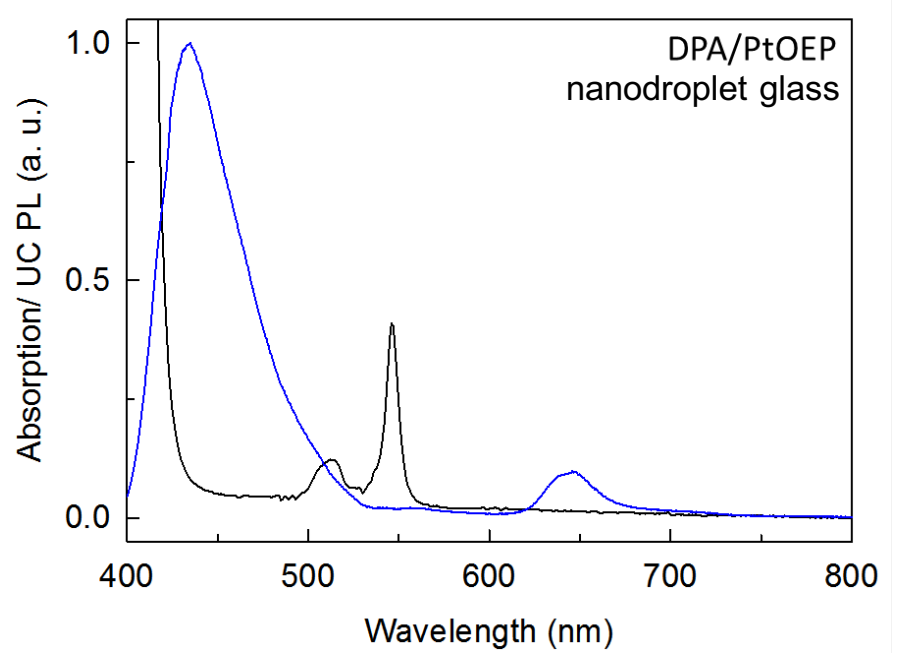

Figure S17: Absorption and upconversion emission spectra of a nanodroplet-containing glassy polymer containing DPA $\left(1.5 \times 10^{-2} \mathrm{M}\right)$ and PtOEP $\left(2 \times 10^{-5} \mathrm{M}\right)$ prepared under ambient conditions. The material was excited at $532 \mathrm{~nm}$ using a Nd:YAG frequency-doubled laser. The dyecontaining glassy polymer displayed upconverted emission at $435 \mathrm{~nm}$ and a weak residual PtOEPphosphorescence at $645 \mathrm{~nm}$.

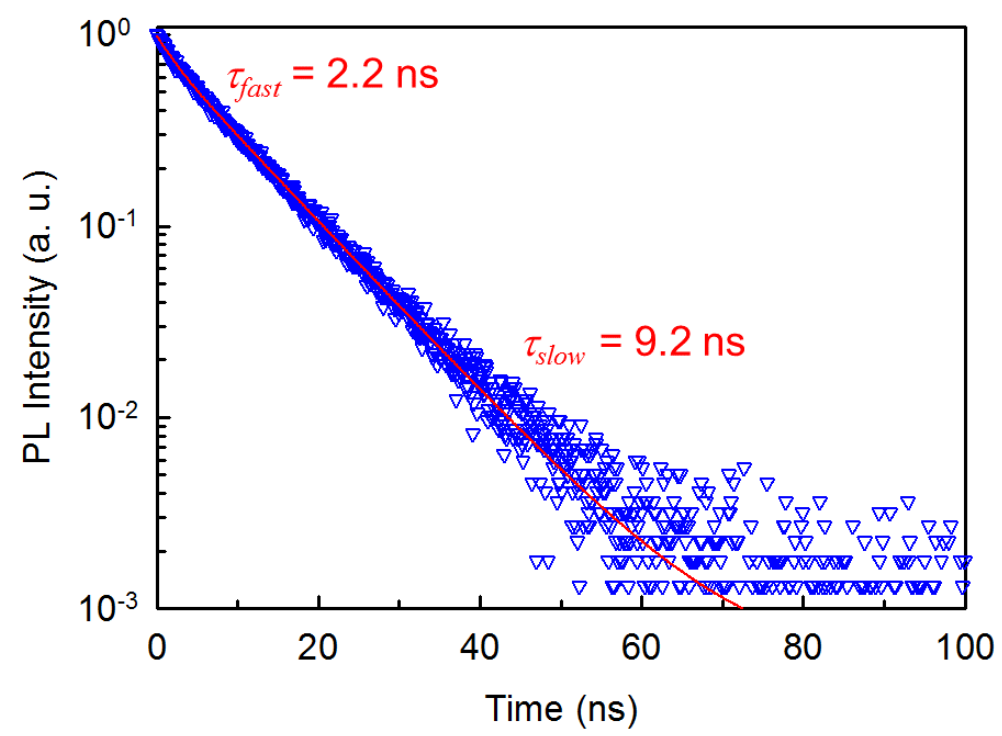

Figure S18: Fluorescence decay at $435 \mathrm{~nm}$ under pulsed UV excitation at $340 \mathrm{~nm}$ in a nanodroplet-containing glassy polymer doped with DPA/PtOEP. The material's PL displays a double exponential decay (red line). This indicates that two different populations of emitters are present. The fast component displays a $\tau_{E f a s t}=2.2 \mathrm{~ns}$, while the slow one shows $\tau_{E}=9.2 \mathrm{~ns}$, in good agreement with the DPA fluorescence lifetime in BMB. According to the relative contribution of the two components, the data suggest that $83 \%$ of the DPA (the slow emitters) resides in the liquid phase of the nanostructured host. 


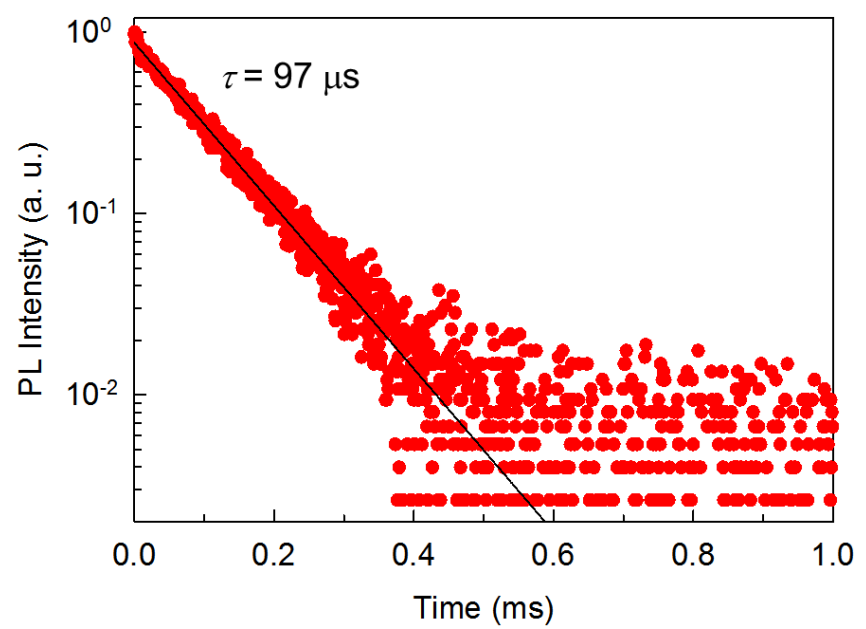

Figure S19: Residual phosphorescence decay in a DPA/PtOEP doped nanodroplet-containing glassy polymer at $645 \mathrm{~nm}$ upon modulated excitation at $532 \mathrm{~nm}$. The residual phosphorescence displays a lifetime of $\sim 100 \mu \mathrm{s}$, which is close to the radiative decay time of the phosphor. This indicates that the chromophore is embedded in a rigid glassy host, protected by oxygen or solvent quenching. ${ }^{[6]}$ This suggests that a small fraction of the PtOEP is segregated in the rigid phase of the material, without experiencing TTET to emitters.

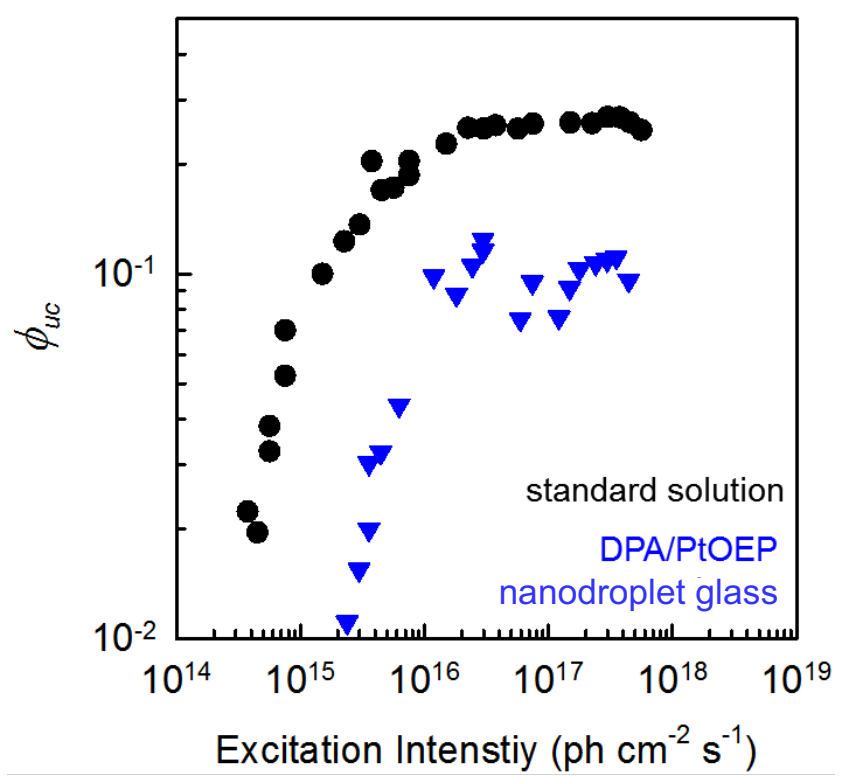

Figure S20: Power density dependence of the upconversion efficiency of the DPA/PtOEP nanodroplet-containing glassy polymer. TTA-UC quantum yield $\phi_{u c}$ as a function of the excitation intensity at $532 \mathrm{~nm}$ for the upconverting nanodroplet-containing polymer (triangles) relative to the standard air-free TTA-UC system in solution (dots). 


\section{Supporting Experimental Section}

\section{Synthesis of materials.}

Chemicals were purchased from Sigma-Aldrich, ABCR, Acros Organics, TCI (Tokyo Chemical Industry Co., Ltd.) or Inochem, Ltd. (Frontier Scientific, Inc) and were used as received. All the nanodroplet-containing polymers were prepared under ambient conditions without prior deoxygenation of the mixture or its single components, unless specifically stated otherwise.

Preparation of red-to-green upconverting nanodroplet-containing glassy polymers. This material was prepared by adapting the procedure detailed in the methods section for nanodroplet-containing glassy polymers without chromophores. A $20 \mathrm{~mL}$ vial equipped with a stirring bar was charged with the components mentioned there, but instead of BMB (500 mg, $10 \mathrm{wt} \%$ ), a palladium(II) tetraphenyltetrabenzoporphyrin (PdTPBP) BMB (500 mg, $10 \mathrm{wt} \%)$-solution $\left(2 \times 10^{-4} \mathrm{M}\right)$ and additionally 9,10-bis(phenylethynyl)anthracene (BPEA, $3.8 \mathrm{mg}$ ) were added. Assuming a glass density of $1 \mathrm{~g} \mathrm{~cm}^{-3}$, the chromophore concentrations are $2 \times 10^{-5} \mathrm{M}$ and $2 \times 10^{-3} \mathrm{M}$ for PdTPBP and BPEA, respectively.

Preparation of red-to-blue upconverting nanodroplet-containing glassy polymers. This material was prepared by adapting the above procedure for red-to-green upconverting nanodroplet-containing glassy polymers, but instead of BPEA, 2,5,8,11-tetrakis(tertbutyl)perylene (TBPe, $4.8 \mathrm{mg}$ ) was used. Assuming a final density of $1 \mathrm{~g} \mathrm{~cm}^{-3}$, the chromophore concentrations are $2 \times 10^{-5} \mathrm{M}$ and $2 \times 10^{-3} \mathrm{M}$ for PdTPBP and TBPe, respectively.

Preparation of dark red-to-yellow upconverting nanodroplet-containing glassy polymers. This material was prepared by adapting the procedure detailed in the methods section for nanodroplet-containing glassy polymers without chromophores. A $20 \mathrm{~mL}$ vial equipped with a stirring bar was charged with the components mentioned before, but instead of BMB (500 mg, $10 \mathrm{wt} \%$ ), a solution of BMB (500 mg, $10 \mathrm{wt} \%$ ) containing palladium(II) octabutoxyphthalocyanine $\left(\operatorname{PdPc}(\mathrm{Bu})_{8}\right)\left(10^{-4} \mathrm{M}\right)$ and additionally rubrene $(5.3 \mathrm{mg})$ were added. Assuming a final density of $1 \mathrm{~g} \mathrm{~cm}^{-3}$, the chromophore concentrations are $10^{-5} \mathrm{M}$ and $10^{-3} \mathrm{M}$ for $\mathrm{PdPc}(\mathrm{Bu})_{8}$ and rubrene, respectively.

Preparation of green-to-blue upconverting nanodroplet-containing elastomers. A $20 \mathrm{~mL}$ vial equipped with a stirring bar was charged with CTAB (250 mg, $5 \mathrm{wt} \%)$, HEA (2hydroxyethyl acrylate; $2.66 \mathrm{~g}, 53.2 \mathrm{wt} \%$ ), tetraethylene glycol diacrylate (TEG-diA; $175 \mathrm{mg}$, $3.5 \mathrm{wt} \%$ ), 1-tert-butyl-3,5-dimethylbenzene (BMB; $500 \mathrm{mg}, 10 \mathrm{wt} \%$ ), ethylene glycol (750 mg, $15 \mathrm{wt} \%$ ) and acrylic acid (AA; $665 \mathrm{mg}, 13.3 \mathrm{wt} \%$ ) (total weight: $5 \mathrm{~g}$ ). Benzoyl peroxide $(10 \mathrm{mg}, 0.2 \mathrm{wt} \%$ of the total mixture) was subsequently added and the mixture was heated to $80{ }^{\circ} \mathrm{C}$ and stirred for $10-15 \mathrm{~min}$ in order to mix all components and obtain a clear mixture. The warm solution was then filtered through a $0.2 \mu \mathrm{m}$ PTFE-filter in a glass vial serving as mould containing $N, N$-dimethylaniline $(10 \mathrm{mg}, 0.2 \mathrm{wt} \%$ of the total mixture). The transparent mixture was then let to stand at $20^{\circ} \mathrm{C}$ until gelation $(\sim 10-15 \mathrm{~min})$, after which the sample was placed into a water bath $\left(15^{\circ} \mathrm{C}\right)$ that served as a cooling medium. After a 
maximum $30 \mathrm{~min}$, the polymerization was completed and a transparent, hard elastomeric block was obtained after breaking the glass mould with a hammer.

Preparation of thermoplastic green-to-blue upconverting nanodroplet-containing glassy polymers without cross-linker. This material was prepared by adapting the procedure detailed in the methods section for green-to-blue upconverting nanodroplet-containing glassy polymers, by omitting the dimethacrylate cross-linker TEG-diMA.

Preparation of green-to-blue upconverting nanodroplet-containing glassy polymer with increased CTAB-content. This material was prepared by adapting the procedure detailed in the methods section for green-to-blue upconverting nanodroplet-containing glassy polymers, but the content of the CTAB surfactant was tripled. The overall BMB- and ethylene glycolcontents as well as the composition of the polymer phase were kept constant: CTAB (750 mg, $15 \mathrm{wt} \%$ ), HEMA (2.28 g, $45.6 \mathrm{wt} \%)$, TEG-diMA (150 mg, $3 \mathrm{wt} \%)$, BMB (500 mg, $10 \mathrm{wt} \%)$, ethylene glycol (750 mg, $15 \mathrm{wt} \%$ ) and MAA (570 mg, $11.4 \mathrm{wt} \%$ ), (total weight $5 \mathrm{~g}$ ). Also, higher amounts of the redox-initiator pair benzoyl peroxide and $N, N$-dimethylaniline were used (both $50 \mathrm{mg}, 1 \mathrm{wt} \%$ of the total weight) to improve polymerization. 


\section{$\underline{T T A-U C \text { quantum yield measurements. }}$}

Upconversion quantum yield measurements for samples containing DPA/ PdOEP have been conducted by using a quasi-collinear setup. The use of relative methods in order to determine TTA-UC quantum efficiencies is routinely used and a widely accepted practice, ${ }^{[7-10]}$ including the use of upconverting dye-pair standards (e.g. DPA/PtOEP in deaerated tetrahydrofuran). ${ }^{[11 \text {, }}$ 12]

In this paper, the definition for the theoretical maximum $\phi_{U C}$ is 0.50 , since the TTA-UC process requires 2 low energy photons to produce 1 high-energy photon. The upconversion luminescence quantum efficiency of UC nanodroplet-containing polymers was determined relative to the maximum TTA-UC yield of the DPA/PtOEP UC pair in deaerated tetrahydrofuran $\left([\mathrm{DPA}]=10^{-2} \mathrm{M},[\mathrm{PtOEP}]=10^{-4} \mathrm{M}\right)$, which has been used as secondary standard according to the following equation

$$
\phi_{U C, u n k}=\phi_{U C, s t d}\left(\frac{A s_{s t d}}{A s_{u n k}}\right)\left(\frac{I_{u n k}}{I_{s t d}}\right)\left(\frac{P_{s t d}}{P_{u n k}}\right)\left(\frac{\eta_{u n k}}{\eta_{s t d}}\right)^{2} \quad, \quad \text { Eq. S1 }
$$

where $\phi_{U C}, A s_{u n k}, I_{u n k}, P_{u n k}$ and $\eta_{u n k}$ represent the quantum yield, absorptance at the excitation intensity, integrated photoluminescence spectral profile, excitation power density, and refractive index of the investigated material. The corresponding terms for the subscript "std" are for the reference quantum counter of DPA/PtOEP pair in deaerated tetrahydrofuran at the identical excitation wavelength. For the relative measurement of $\phi_{U C, u n k}, I_{s t d}$ has been kept constant at $100 \mathrm{~mW} \mathrm{~cm} \mathrm{~m}^{-2}$ at $532 \mathrm{~nm}$. With this excitation power density far beyond the excitation threshold intensities $I_{t h}$ of the samples and the standard, $\phi_{U C, s t d}$ is constant, maximum and fixed at $0.26 .^{[13]}$ This value and its dependence on the excitation power density has been measured using Equation S1 with the laser dye Rhodamine $6 \mathrm{G}\left(10^{-5} \mathrm{M}\right.$ in ethanol) as reference material. ${ }^{[13-16]}$ This value is similarly high compared to the $\phi_{U C}$ values reported by several groups for a range of TTA-UC dye pairs in solution, such as DPA/PdOEP (0.18), ${ }^{[15]}$ perylene/PdTPBP $(0.38)^{[16]}$ or DPA/PdTPP $(0.22)^{[17]}$ and is in very good agreement with the $\phi_{U C}$ values already reported for DPA/PtOEP $(>0.23){ }^{[10]}$

The recorded spectra have been corrected for the setup's optical response. The secondary standard solution was freshly prepared and characterized before each set of measurements. In such a way, we can avoid to perform the spectral correction for all the UC samples. The refractive index of the nanodroplet-containing polymers was assumed to be similar to the one of BMB $\left(1.496 \eta_{\mathrm{D}}{ }^{20}\right)$ and takes into account the different linear optical properties of the investigated material and the standard, which affect the angular dependence of the photon flux emitted isotropically by the source and thus the photon detection ability of the experimental setup. ${ }^{[18]}$ It should be noted that in the high excitation power density limit the $\phi_{U C}$ does not depend on the excitation intensity anymore and reaches its constant maximum value. In order to confirm the results obtained with the quasi collinear setup and avoid trivial error due to the bulk sample geometry, the yield measurements have been repeated with an integrating sphere. 
The maximum $\phi_{U C}$ reported were measured on three independently prepared samples and using high excitation intensity $\left(100 \mathrm{~mW} \mathrm{~cm}^{-2}\right.$ at $\left.532 \mathrm{~nm}\right)$ in order to obtain power densityindependent quantum efficiencies. In order to analyze determine quantum efficiencies at power intensities close or below $I_{t h}$ (Figure 3e), we first measured the UC signal of the standard as a function of the excitation intensity and used this data set to establish the dependence between the $\phi_{U C}$ of the standard and the excitation intensity. We then measured the UC-intensities of the upconverting nanodroplet-containing polymers as function of excitation intensity and correlated these values with the values of the standard at the same excitation intensity.

Quasi collinear setup ${ }^{[4]}$. This setup was chosen in order to minimize the effects related to high optical densities of the samples. The photoluminescence (PL) signals were recorded from the overall excited volume to take into account the difference in the laser beam attenuation within the samples.

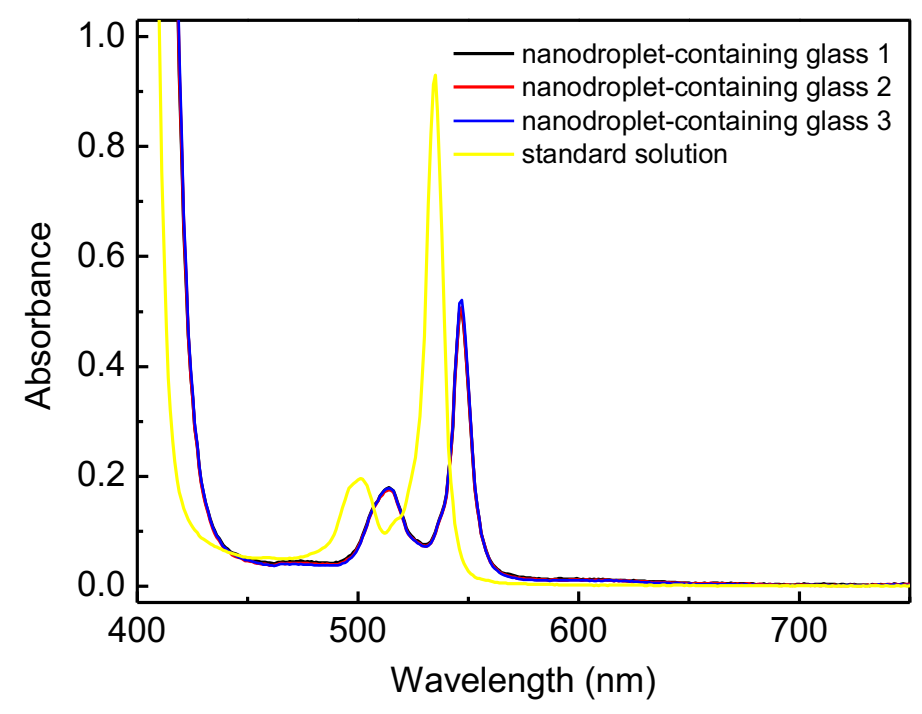

Figure S21: Absorption spectra of DPA/PdOEP doped nanodroplet-containing glassy polymers and of the air-free standard DPA/PtOEP solution in THF. The spectra have been recorded under normal incidence. The solution was sealed in a quartz cuvette with $0.1 \mathrm{~cm}$ of optical path. The polymer samples had a maximum absorbance of $\sim 0.5$ with an optical path length of $0.5 \mathrm{~cm}$. 
Table S1. Absorptance at $532 \mathrm{~nm}$ and quantum yield $\Phi_{U C}$ of three different nanophase-separated samples prepared under ambient conditions and measured with the quasi-collinear setup.

\begin{tabular}{cccc}
\hline Sample & $\begin{array}{c}\text { Absorbance } \\
(\mathbf{0 . 1} \text { cm) }\end{array}$ & $\begin{array}{c}\text { Absorptance } \\
(\mathbf{0 . 1} \text { cm })\end{array}$ & $\boldsymbol{\Phi}_{\boldsymbol{u c}}$ \\
\hline D1 & $7.6900 \mathrm{e}-3$ & 0.0176 & 0.1693 \\
D2 & $7.4100 \mathrm{e}-3$ & 0.0169 & 0.1528 \\
D3 & $7.3400 \mathrm{e}-3$ & 0.0168 & 0.1103 \\
average & - & - & $\mathbf{0 . 1 4 4} \pm \mathbf{0 . 0 3}$ \\
standard & 0.6964 & 0.7988 & $\mathbf{0 . 2 6 0 0}$ \\
\hline
\end{tabular}

Integrating sphere setup. To further validate our results, the relative method was also used with the integrating sphere setup, which should remove any detrimental effect of the scattering of the excitation light that could avoid a proper determination of the absorptance of the samples. Adapting the protocol by DeMello et al. ${ }^{[19]}$, the amount of absorbed photons has been calculated by considering the ratio between the laser intensity in the sphere with and without the sample. The upconverted light generated by self-absorption and by re-absorption of the scattered laser light has been taken into account by measuring the signal light generated in the sphere while the laser beam did not hit directly the sample. Every sample has been measured twice, from the "front" and the "back".

Table S2. Quantum yield $\Phi_{U C}$ of the DPA/PdOEP doped nanodroplet-containing glassy polymers measured with the integrating sphere setup.

\begin{tabular}{cc}
\hline Sample & $\boldsymbol{\Phi}_{u c}$ \\
\hline D1 & 0.1650 \\
D1- backside & 0.1740 \\
D2 & 0.1716 \\
D2- backside & 0.1445 \\
D3 & 0.1326 \\
D3- backside & 0.1452 \\
average & $\mathbf{0 . 1 5 5 5} \pm \mathbf{0 . 0 1 7}$ \\
standard & $\mathbf{0 . 2 6 0 0}$ \\
\hline
\end{tabular}


Table S3. Quantum yields $\Phi_{U C}$ of DPA/PtOEP doped nanodroplet-containing glassy polymers, prepared and operated under ambient conditions and measured with the integrating sphere setup.

\begin{tabular}{cc}
\hline Sample & $\boldsymbol{\Phi}_{\boldsymbol{u c}}$ \\
\hline S1 & 0.10 \\
S2 & 0.08 \\
S3 & 0.05 \\
average & $\mathbf{0 . 0 8} \pm \mathbf{0 . 0 3}$ \\
standard & $\mathbf{0 . 2 6 0 0}$ \\
\hline
\end{tabular}

Table S4. Quantum yields $\Phi_{U C}$ the rubrene/( $\left.\mathrm{Pd}(\mathrm{OBu})_{8} \mathrm{Pc}\right)$ doped nanodroplet-containing glassy polymers, prepared and operated under ambient conditions and measured with the integrating sphere setup.

\begin{tabular}{cc}
\hline Sample & $\boldsymbol{\Phi}_{u c}$ \\
\hline R1 & 0.14 \\
R1- backside & 0.18 \\
R2 & 0.11 \\
R2- backside & 0.17 \\
R3 & 0.15 \\
R3- backside & 0.16 \\
average & $\mathbf{0 . 1 5} \pm \mathbf{0 . 0 3}$ \\
\hline
\end{tabular}




\section{Supporting Discussion}

\section{Thermal Properties.}

The glass transition temperature $T_{g}$ observed for the ethylene glycol plasticized poly(HEMAco-MAA-co-TEG-diMA)/BMB nanodroplet-containing glassy polymers with or without upconversion dyes were established by DSC as $48-52^{\circ} \mathrm{C}$ (Figure S5). Subsequent DSC measurements on materials in which the surfactant $\mathrm{CTAB}$ was omitted or its mass fraction varied (Supporting Figure S22a and S25) did not lead to a significantly different $T_{g}$, indicating that glass transition originates from the polymer phase.

In fact, the glass transition temperatures $T_{g}$ observed for the nanodroplet-containing polymers can be rationalized by considering the $T_{g}$ values of HEMA-co-MAA copolymers and subsequently taking into account the effects arising from plasticization of ethylene glycol, which was not primarily used to act as a plasticizer, but rather to adjust the refractive index, so as to match the refractive indices of the two phases. The effects of minor $(0-5 \mathrm{wt} \%)$ dimethacrylate cross-linking on poly(HEMA) have been previously investigated and were found to have only a minor influence on the $T_{g}\left(\sim 5^{\circ} \mathrm{C}\right.$ with $2 \mathrm{wt} \%$ cross-linker $) .{ }^{[3]}$ These results were confirmed for the non-cross-linked plasticized poly(HEMA-co-MAA-co-TEGdiMA)/BMB nanodroplet-containing glassy polymer, which displayed a $T_{g}=53{ }^{\circ} \mathrm{C}$ (Supporting Figure S23).

The thermal properties of HEMA-co-MAA copolymers prepared by initiation with azobisisobutyronitrile (AIBN) have been previously investigated, both theoretically and experimentally by Verhoeven et al. ${ }^{[2]}$ The internal ratio of HEMA/MAA in the nanophaseseparated glasses studied here corresponds to $80 / 20 \mathrm{w} / \mathrm{w}$ or $73 / 27 \mathrm{~mol} / \mathrm{mol}$ (see methods section). HEMA-co-MAA copolymers of this composition were reported to display a $T_{g}$ of $\sim 97{ }^{\circ} \mathrm{C}(310 \mathrm{~K})$, which is in good agreement with the value $T_{g}=94{ }^{\circ} \mathrm{C}$ measured by us for non-plasticized poly(HEMA-co-MAA-co-TEG-diMA)/BMB nanodroplet-containing glassy polymer (Figure S22b). In the same publication, Verhoeven et al. investigated the plasticizing effect of $15 \mathrm{wt} \% 400 \mathrm{~g} / \mathrm{mol}$ poly(ethylene glycol) in 40/60 w/w copolymers of HEMA-coMAA, which displayed a $T_{g} \approx 40^{\circ} \mathrm{C}$. 

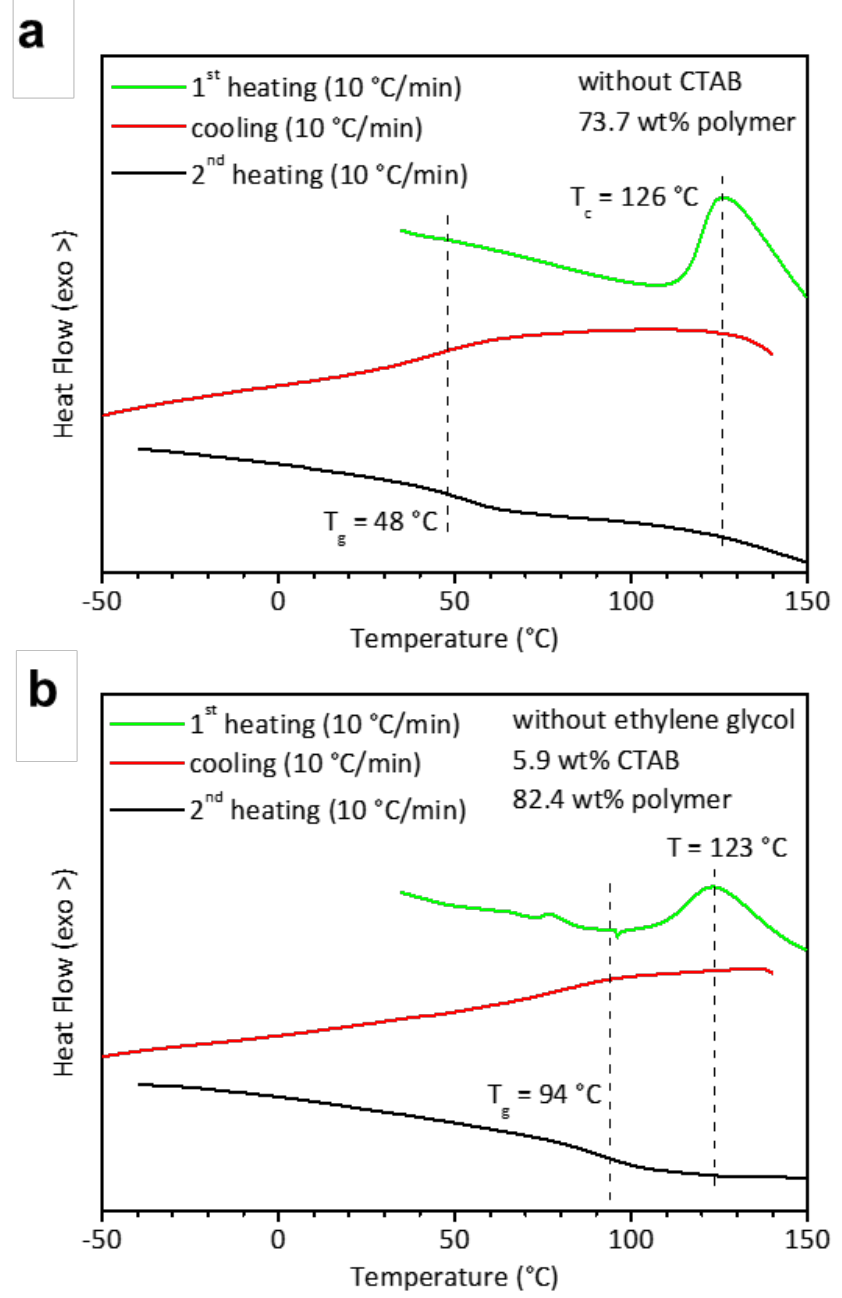

Figure S22: DSC scans of poly(HEMA-co-MAA-co-TEG-diMA)/BMB nanodroplet-containing glassy polymers made without either CTAB (a) or ethylene glycol (b). The materials were prepared using the same procedure detailed in the methods section for the preparation of nanodroplet-containing glassy polymers without chromophores. The material prepared without CTAB showed no change of the glass transition temperature range $T_{g}=48-53{ }^{\circ} \mathrm{C}$ during the second heating cycle (Figure S5), whereas the material prepared without ethylene glycol $\left(T_{g}=94^{\circ} \mathrm{C}\right)$ displayed similar glass transition temperatures as poly(HEMA-co-MAA). ${ }^{[2]}$ As expected, this data confirms that ethylene glycol acts as a plasticizer and resides in the polymer phase. 


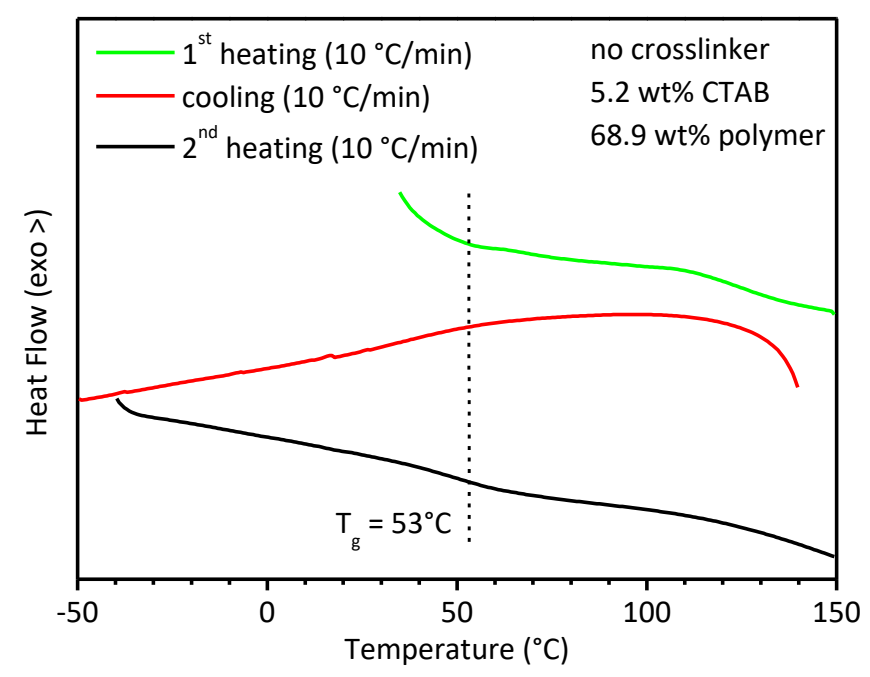

Figure S23: DSC scans of nanophase-separated ethylene glycol plasticized poly(HEMA-coMAA)/BMB nanodroplet-containing glassy polymers made without cross-linker. This material was prepared by adapting the procedure detailed in the methods section for nanodroplet-containing glassy polymers but without cross-linker and chromophores and displays a glass transition temperature in the same range $T_{g}=48-53^{\circ} \mathrm{C}$ during the second heating cycle. 


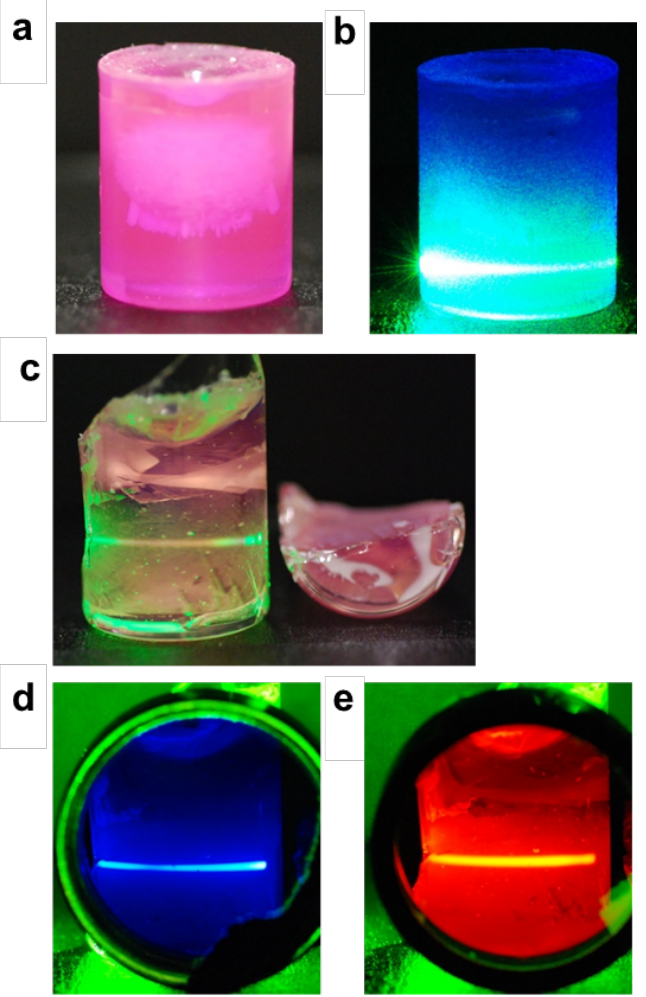

Figure S24: Pictures of nanodroplet-containing glassy polymers doped with DPA/PdOEP made without (a-b) ethylene glycol or (c-e) surfactant CTAB. (a) Pictures of a sample taken under ambient illumination and (b) irradiated with $\sim 225 \mathrm{~mW} \mathrm{~cm}^{-2}$ at $543 \mathrm{~nm}$ (HeNe laser). The sample seems to be macrophase-separated (white inclusion) but still shows some blue upconverted light. (c) Pictures of a sample taken under ambient illumination and irradiated with $\sim 225 \mathrm{~mW} \mathrm{~cm}^{-2}$ at $543 \mathrm{~nm}$ (HeNe laser) seen through (d) a $500 \mathrm{~nm}$ short-pass or (e) $600 \mathrm{~nm}$ long-pass filter. The homogenous, transparent sample cannot be separated from the glass mould and displays mainly downconverted and some weak upconverted luminescence. 

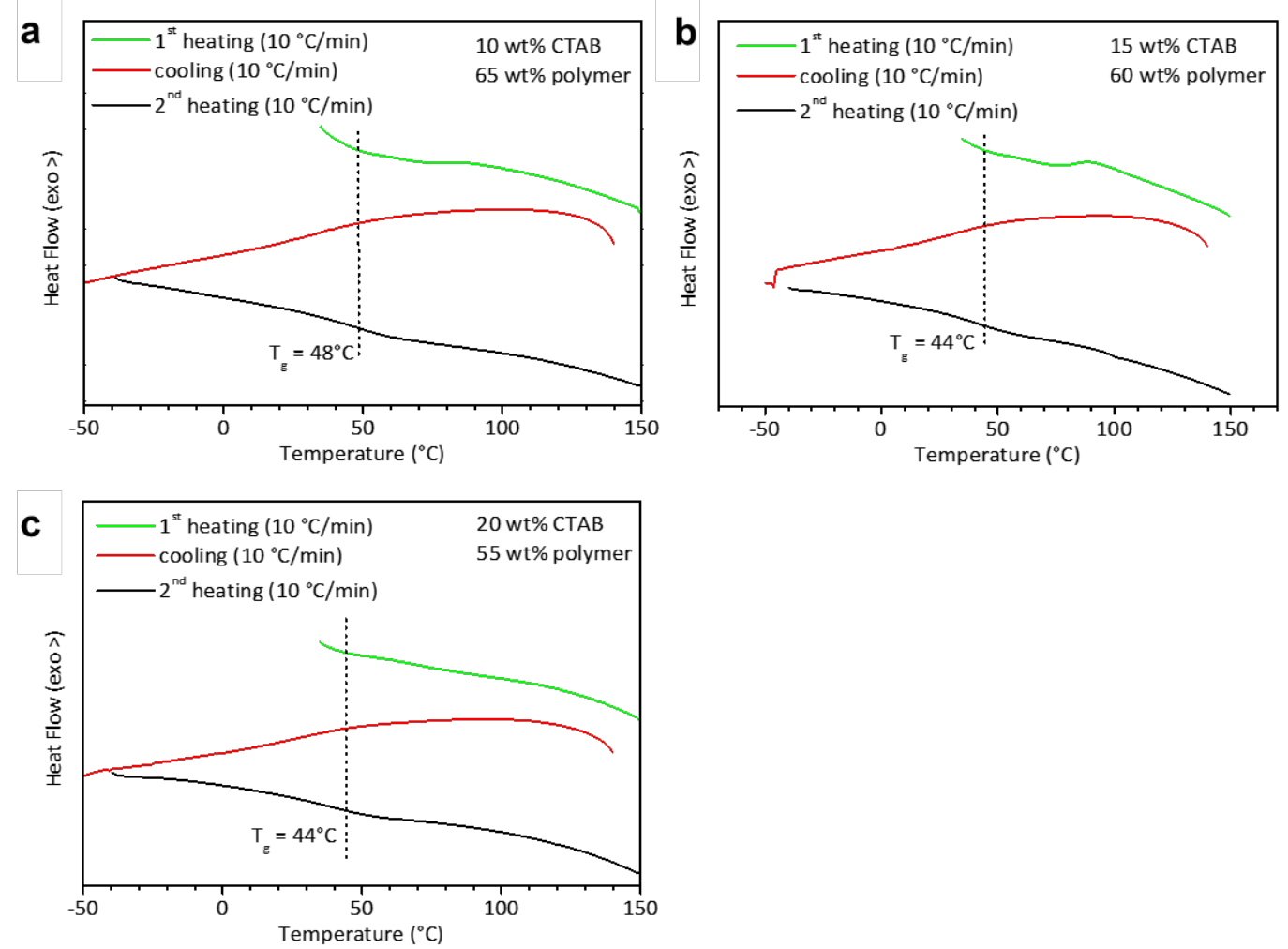

Figure S25: DSC scans of nanodroplet-containing glassy polymers without dyes made with varying amounts of CTAB-surfactant. The previously discussed polymer samples (Figure S5) contain $70 \mathrm{wt} \%$ polymer and $5 \mathrm{wt} \% \mathrm{CTAB}$-surfactant and display similar glass transition temperatures $T_{g}$ compared to samples containing(a) $10 \mathrm{wt} \% \mathrm{CTAB}$ and $65 \mathrm{wt} \%$ polymer, (b) $15 \mathrm{wt} \% \mathrm{CTAB}$ and $60 \mathrm{wt} \%$ polymer and (c) $20 \mathrm{wt} \% \mathrm{CTAB}$ and $55 \mathrm{wt} \%$ polymer. 


\section{Photophysical Properties.}

Fluorescence Quantum Yield. The DPA fluorescence quantum yield has been measured by a relative method using a dilute solution of DPA in THF, which shows a quantum yield of 0.96. The fluorescence quantum yield observed for DPA in BMB is $78 \%$. The lower TTA-UC efficiency observed in the nanodroplet-containing glassy polymer can thus be partially ascribed to the reduced fluorescence yield of the emitter.
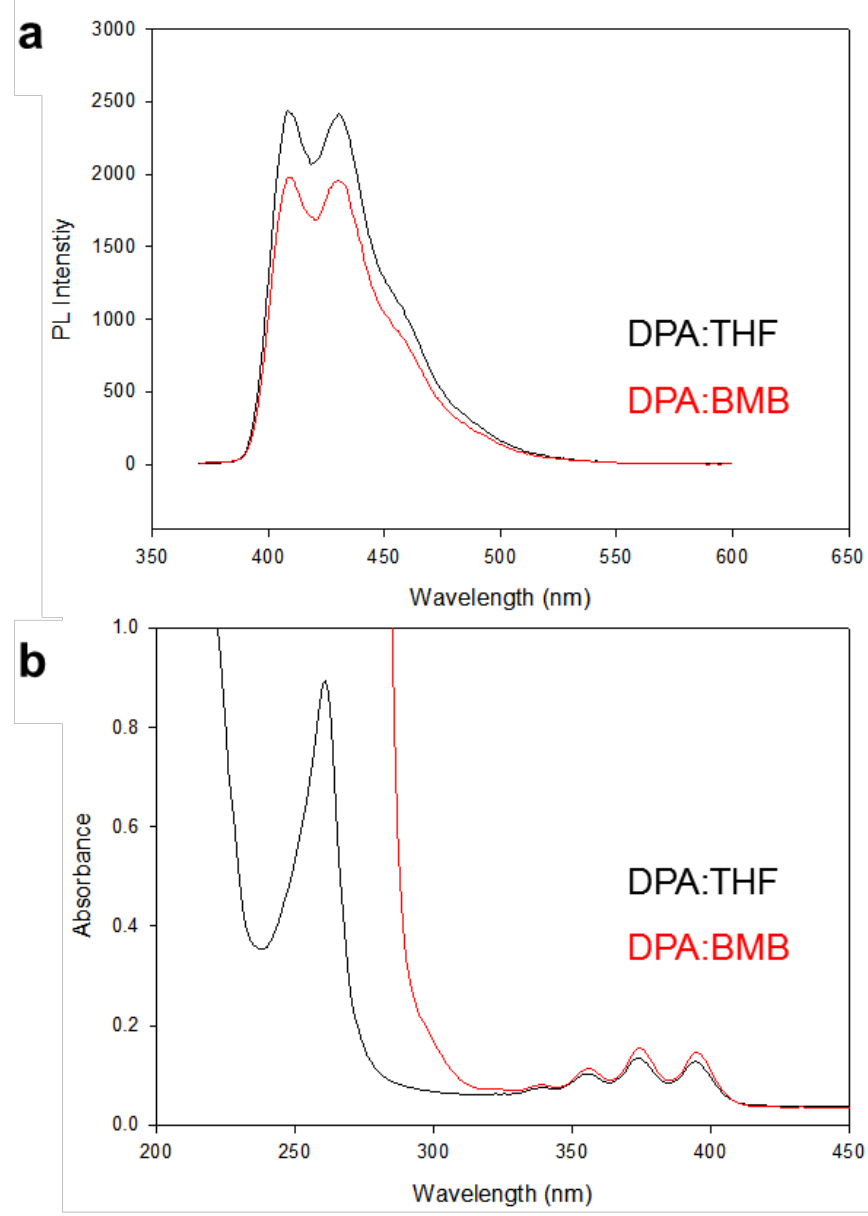

Figure S26: BMB or THF solutions containing DPA with a concentration of $10^{-2} \mathrm{M}$ and $10^{-5} \mathrm{M}$, respectively. (a) Photoluminescence spectra of a BMB and a THF solution upon irradiation at $355 \mathrm{~nm}$, corrected for the systems absorbance. (b) Absorption spectra of the THF and BMB solutions, measured in quartz cuvettes (optical path $0.1 \mathrm{~cm}$ ). 


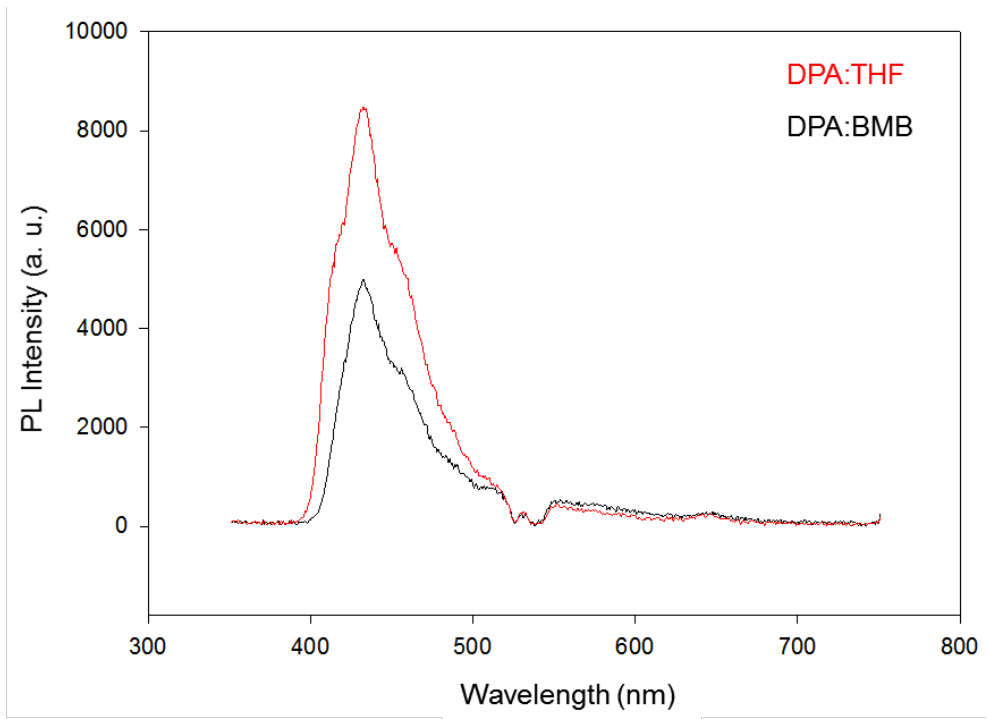

Figure S27: Green-to-blue upconversion in air-free BMB or THF solutions containing PtOEP $\left(\mathbf{c}=\mathbf{1 0}^{-4} \mathbf{M}\right)$ and DPA $\left(\mathbf{c}=\mathbf{1 0}^{-2} \mathbf{M}\right)$. Emission spectra recorded from a BMB and a THF solution upon irradiation at $533 \mathrm{~nm}$. For the BMB solution, an upconversion quantum yield of $\Phi_{U C}=16 \%$ was found, which is lower than that in THF $\left(\Phi_{U C}=26 \%\right)$.

TTA Kinetics. The determination of $\Phi_{T T A}$ and the emitter triplet lifetime $\tau_{T}$ is possible by measuring the time-dependent decay of the upconverted fluorescence. Gratifyingly, samplescontaining PdOEP or PtOEP as sensitizer displayed $\Phi_{T T A} \approx 1$ and $\tau_{T} \approx 550-750 \mu \mathrm{s} .^{[13]}$ The DPA triplet decay rates $k_{T}=\left(\tau_{T}\right)^{-1}$ were determined by fitting the decay at long times in the regime of slow annihilation $\left(k_{T} \gg k_{T T A}, t>1 \mathrm{~ms}\right)$ with a single exponential function. ${ }^{[12,20]}$ In order to obtain the triplet-triplet annihilation efficiency $\Phi_{T T A}$, the value obtained for $\tau_{T}$ was subsequently used to fit the short-time decay (regime of fast annihilation), according to equation 2 , in order to evaluate $\Phi_{T T A}{ }^{[21]}$

$$
I_{U C}(\mathrm{t}) \propto\left(\frac{1-\phi_{T T A}}{\exp \left(k_{T}\right)-\phi_{T T A}}\right)^{2} \quad \text { Eq. S2 }
$$




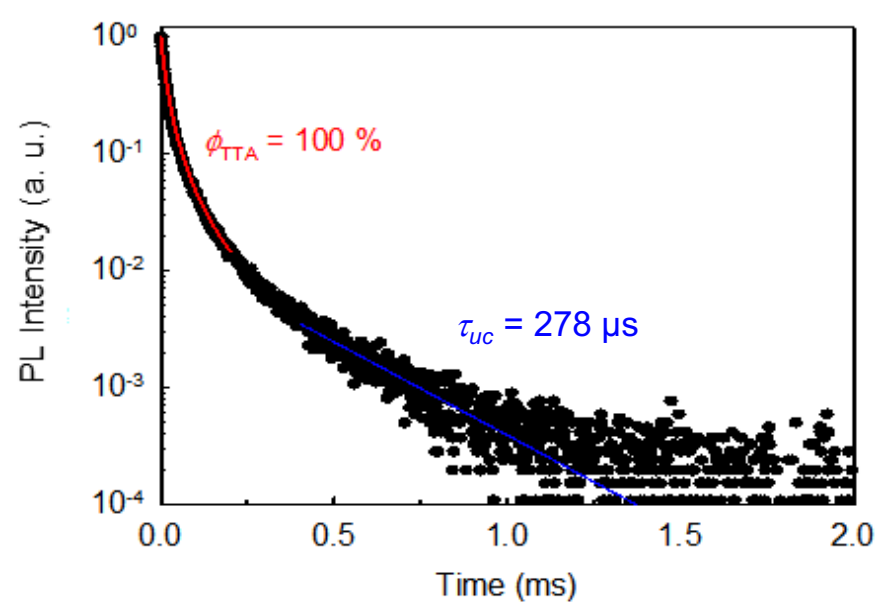

Figure S28: Luminescence decay at $435 \mathrm{~nm}$ upon modulated excitation at $532 \mathrm{~nm}\left(100 \mathrm{~mW} \mathrm{~cm}^{-2}\right)$ of the DPA/PtOEP doped nanodroplet-containing glassy polymer prepared under ambient conditions. At short times, the material displays a TTA efficiency of near unity and a $\tau_{u c}=278 \mu \mathrm{s}$ at long times. This corresponds to a $\tau_{T}=556 \mu \mathrm{s}$, which is lower than the values found in THF solutions $\left(\tau_{T} \approx 2.2 \mathrm{~ms}\right)$ due to presence of residual oxygen. ${ }^{[12]}$

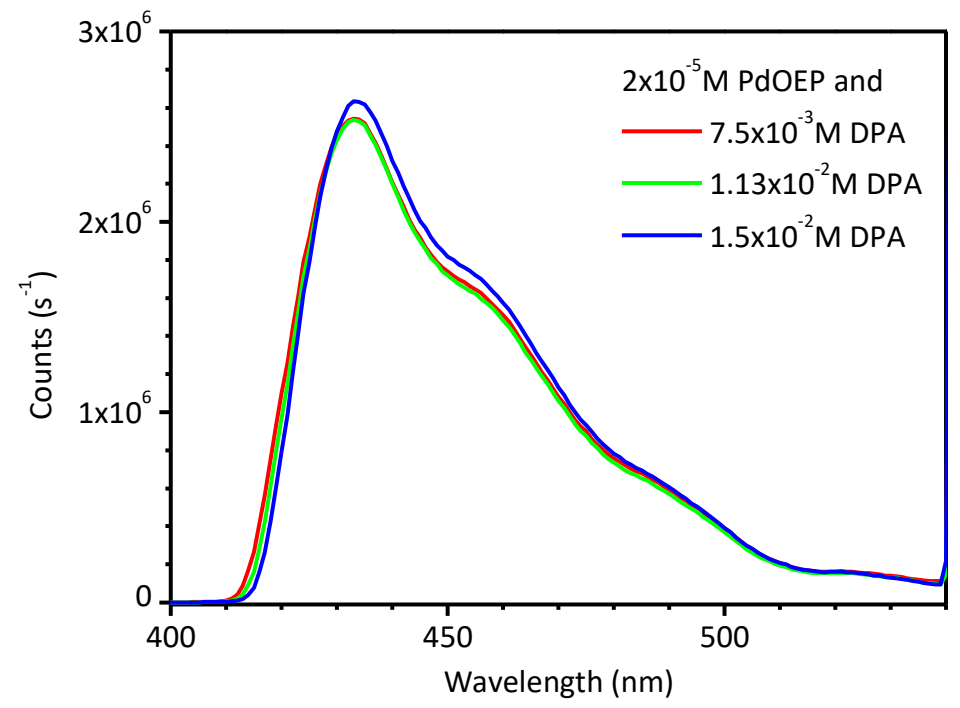

Figure S29: Photoluminescence spectra of DPA/PdOEP doped nanodroplet-containing glassy polymers containing varying amounts of DPA. All the samples were doped with PdOEP $\left(2 \times 10^{-5} \mathrm{M}\right)$ and with varying amounts of DPA ranging from $7.5 \times 10^{-3} \mathrm{M}$ to $1.5 \times 10^{-2} \mathrm{M}$ and were excited with a $2 \mathrm{~mW}, 543 \mathrm{~nm}$ HeNe laser at a power density of $\sim 275 \mathrm{~mW} \mathrm{~cm}^{-2}$. The emission intensity was found to be very similar for all the samples, which is indicative for a similar quantum yield within this range. ${ }^{[13]}$ 


\section{Supporting Movie}

Movie M1: Ethylene glycol plasticized poly(HEMA-co-MAA-co-TEG-diMA)/BMB nanodropletcontaining glassy polymer doped with both the sensitizer PdOEP $\left(2 \times 10^{-5} \mathrm{M}\right)$ and the emitter DPA $\left(1.5 \times 10^{-2} \mathrm{M}\right)$, irradiated with a $2 \mathrm{~mW}$ green $\mathrm{HeNe}$ laser at $543 \mathrm{~nm}$ (power density $\sim 225 \mathrm{~mW} \mathrm{~cm} \mathrm{c}^{-2}$ ). The blue upconverted light is visible in the dark and under ambient lightening. The materials' toughness is demonstrated by hitting it with a hammer.

\section{Supporting References}

[1] J. Kolařík, in Behavior of Macromolecules, Springer Berlin Heidelberg, Berlin, Heidelberg 1982, p. 119.

[2] J. Verhoeven, R. Schaeffer, J. A. Bouwstra, H. E. Junginger, Polymer 1989, 30, 1946.

[3] W. E. Roorda, J. A. Bouwstra, M. A. de Vries, H. E. Junginger, Pharm. Res. 1988, 5, 722.

[4] A. Monguzzi, M. Mauri, A. Bianchi, M. K. Dibbanti, R. Simonutti, F. Meinardi, J. Phys. Chem. C 2016, 120, 2609.

[5] H. C. Brown, M. Grayson, J. Am. Chem. Soc. 1953, 75, 20.

[6] A. Monguzzi, M. Frigoli, C. Larpent, R. Tubino, F. Meinardi, Adv. Funct. Mater. 2012, 22, 139.

[7] Y. Murakami, Chem. Phys. Lett. 2011, 516, 56.

[8] K. Borjesson, P. Rudquist, V. Gray, K. Moth-Poulsen, Nat Commun 2016, 7.

[9] S. Baluschev, V. Yakutkin, T. Miteva, G. Wegner, T. Roberts, G. Nelles, A. Yasuda, S. Chernov, S. Aleshchenkov, A. Cheprakov, New J. Phys. 2008, 10, 013007.

[10] K. Xu, J. Zhao, D. Escudero, Z. Mahmood, D. Jacquemin, J. Phys. Chem. C 2015, $119,23801$.

[11] T. Ogawa, N. Yanai, A. Monguzzi, N. Kimizuka, Sci. Rep. 2015, 5, 10882.

[12] A. Monguzzi, M. Mauri, M. Frigoli, J. Pedrini, R. Simonutti, C. Larpent, G. Vaccaro, M. Sassi, F. Meinardi, J. Phys. Chem. Lett. 2016, 2779.

[13] A. Monguzzi, R. Tubino, S. Hoseinkhani, M. Campione, F. Meinardi, Phys. Chem. Chem. Phys. 2012, 14, 4322.

[14] M. Montalti, A. Credi, L. Prodi, M. T. Gandolfi, Handbook of Photochemistry, Taylor\&Francis, Boca Raton 2006.

[15] R. S. Khnayzer, J. Blumhoff, J. A. Harrington, A. Haefele, F. Deng, F. N. Castellano, Chem. Commun. 2012, 48, 209.

[16] S. Hoseinkhani, R. Tubino, F. Meinardi, A. Monguzzi, Phys. Chem. Chem. Phys. 2015, 17, 4020.

[17] K. Sripathy, R. W. MacQueen, J. R. Peterson, Y. Y. Cheng, M. Dvorak, D. R. McCamey, N. D. Treat, N. Stingelin, T. W. Schmidt, J. Mater. Chem. C 2015, 3, 616.

[18] J. R. Lakowicz, Principles of Fluorescence Spectroscopy, Springer Science+Business Media, LLC, New York 2006.

[19] J. C. de Mello, H. F. Wittmann, R. H. Friend, Adv. Mater. 1997, 9, 230.

[20] M. Pope, C. E. Swenberg, Electronic Processes in Organic Crystals and Polymers, Oxford University Press, 1999.

[21] T. W. Schmidt, Y. Y. Cheng, B. Fuckel, T. Khoury, R. G. C. R. Clady, M. J. Y. Tayebjee, N. J. Ekins-Daukes, M. J. Crossley, J. Phys. Chem. Lett. 2010, 1, 1795. 